\title{
EL SISTEMA PRODUCTIVO LOCAL EN TORNO A LA AGRICULTURA INTENSIVA ALMERIENSE
}

Francisco J. FERRARO GARCÍA* Buenaventura AGUILERA DÍAZ** José Ángel AZNAR SÁNCHEZ***

\section{RESUMEN}

En este artículo se presentan los resultados cualitativos y cuantitativos del estudio realizado a partir de la encuesta a un panel de expertos sobre el sistema productivo local en torno a la agricultura de Almería. Las conclusiones apuntan que, aunque el crecimiento ha sido sostenido y diversificado, debe hacerse un esfuerzo para potenciar los factores más dinámicos del sistema tratando de endogeneizar variables tan importantes como la innovación promover la diversificación productiva del conjunto del sistema, abordar la expansión hacia nuevos mercados y controlar los efectos adversos del uso intensivo de los factores de producción.

\section{EL MARCO INTERPRETATIVO}

El desarrollo económico siempre ha sido una aspiración colectiva de los pueblos expresada de mil formas diferentes, y los economistas, desde los clásicos, se han preocupado por el crecimiento económico a largo plazo, si bien en ciertos periodos históricos su quehacer ha estado focalizado en problemas más inmediatos derivados de la coyuntura o de la propia dinámica del pensamiento económico. Pero es desde hace algo más de nna década cuando la Economía ha retomado su preocupación por el crecimiento a largo plazo como uno de los objetos funda-

* Catedrático de Economía Aplicada. Universidad de Sevilla.

** Analista de Consultores de las Administraciones Públicas.

*** Profesor de Economía Aplicada. Universidad de Almería. 
mentales de investigación. A ello han contribuido las nuevas aportaciones de $]$ teoría del crecimiento en la que obras como las de Romer (1986, 1990), Luca (1988), Rebelo (1988) o Blanchard (1991), han abierto nuevas perspectivas a la limitaciones del modelo Solow (1956) y de las teorías «heterodoxas» del desarrc 1lo. Fruto de este trabajo es la emergencia de múltiples obras que han ido perfec cionando los soportes teóricos y metodológicos, a la vez que la disponibilidad d una mayor información estadística ha permitido la contrastación de las dinámica de crecimiento y, en particular, de las tendencias a la convergencia o divergenci a largo plazo de países, regiones o provincias.

Entre los resultados más significativos de las nuevas líneas de investigació destaca el carácter no decreciente del rendimiento de los factores reproducible (Rebelo, 1986), lo que cuestiona la inevitabilidad de la convergencia a largo pla zo de las economías, y un cambio de orientación fundamental al introducir el cam bio tecnológico como variable endógena en algunos de los nuevos modelos (Romes 1986; Lucas, 1988). Las nuevas aportaciones, además, abren el camino a la valo ración del capital físico, de la innovación tecnológica y del capital humano y sl acumulación, lo que permite a su vez dar cabida al papel de las economías exter nas o externalidades en los procesos de desarrollo. La consideración de la externalidades y, sobre todo, de los efectos de desbordamiento (spillovers) enfatiz: el carácter autoalimentado de la dinámica de crecimiento y, consecuentemente, li no convergencia de las sendas de crecimiento de países y regiones.

Una de las razones del resurgimiento de las economías externas en la literatu ra económica ha sido su aplicación al modelo industrial italiano, donde se identi fican concentraciones de empresas en el territorio motivadas fundamentalmente po la existencia de externalidades que reducen los costes de producción, crean un: «atmósfera industrial» que facilita una dinámica innovadora, atraen a nuevas em. presas con actividades complementarias, se diversifican los servicios y se gener; una acumulación de conocimientos. Estas concentraciones de empresas vinieron : denominarse «distritos industriales» (Becattini, 1992), que pueden definirse comc entidades territoriales que se caracterizan por la presencia de una comunidad d personas y de una población de empresas dentro de un área delimitada, tanto histórica como territorialmente; las pequeñas y medianas empresas que conforman es población están especializadas en una o varias fases o funciones de una industric concreta o sus subsidiarias (Ottati, 1996), beneficiándose cada empresa de operas a la escala apropiada, así como de las externalidades derivadas de la concentración y de la especialización de las otras empresas.

Algunos autores (Sanromá, 1996) definen el concepto de «sistemas productivos locales» (o «sistema local de empresas») para concentraciones de empresas en el territorio, semejante al distrito industrial, pero de forma más amplia y flexible. que puede abarcar realidades diversas, pero caracterizadas por una serie de rasgos básicos: pequeñas y medianas empresas, ámbito geográfico limitado, actividad 
principal determinada y cierta división del trabajo. Dentro de estos sistemas, las relaciones entre las empresas se caracterizan por una mezcla de competencia (en precios, calidad, diseño y condiciones de entrega) y cooperación (en la planificación, en la experimentación con nuevas tecnologías, en la producción para clientes demasiado grandes, etc.) (Brusco, 1996).

De lo anteriormente expuesto se pueden extraer dos conclusiones. En primer lugar, que los sistemas productivos locales disponen de una serie de externalidades o recursos compartidos que permite determinar el grado de acercamiento de un conjunto o concentración de empresas a un sistema que podemos calificar de ideal. En segundo lugar, que existen una serie de factores que explican la competitividad del sistema. Entre ellos, como destacan Becattini y Rullani (1996), la especificidad de la producción «local» se basa en los procesos de adquisición de conocimientos que sedimentan saberes diferenciados difícilmente transferibles.

Finalmente es necesario hacer una reflexión sobre este tipo de concentraciones en relación con la intemacionalización de la actividad económica, ya que si bien la concentración productiva es un factor determinante de la eficiencia de empresas y territorios, la dinámica globalizadora, con una creciente integración de las economías y con la progresiva reducción de los costes de transporte, puede significar que los espacios más desarrollados de la Unión Europea tiendan a concentrar a actividades económicas, que actualmente se producen eu otras zonas, reduciendo con ello la producción y, por tanto, renta y empleo, de espacios periféricos. Estas consideraciones deben llevar a la necesidad de potenciar en teritorios que se muestran dinámicos, como Almería, los factores creadores o que retienen las economías externas, evitando así la generación de desplazamientos de actividades hacia regiones más desarrolladas. Asimismo es conveniente valorar que una excesiva especialización productiva puede hacer vulnerable a un territorio ante un cambio en la demanda o cualquier contingencia de los mercados; vulnerabilidad que será menor en la medida en que se desarrollen actividades complementarias y se produzcan externalidades dinámicas.

\section{LA ECONOMÍA ALMERIENSE EN PERSPECTIVA}

La provincia de Almería ha experimentado importantes transformaciones económicas y sociales en los últimos treinta años. Hasta los años sesenta cualquier análisis socioeconómico revelaba la profunda depresión económica en la que estaba sumida la provincia, mostrando un menor nivel de desarrollo, no sólo respecto a la media española, sino al resto de las provincias andaluzas. Sin embargo, este declive mantenido durante largo tiempo se interrumpió a principios de la década de los setenta cuando la economía almeriense empieza a manifestar síntomas de recuperación. Desde entonces, los indicadores económicos de desarrollo empiezan 
a mostrar valores positivos superiores a los de su entorno, lo que le ha permitide ir aumentando su peso relativo en Andalucía y España.

La evolución demográfica da buena muestra de esos cambios. La población d $\epsilon$ la provincia permaneció prácticamente estancada durante los primeros setenta años del presente siglo, mientras que la población del conjunto de Andalucía y Españá crecía ininterrumpidamente. Sin embargo, a partir de 1970 Almería presenta unas tasas anuales de crecimiento demográfico superiores a la media española y andaluza, rompiendo la histórica tendencia a la reducción de su peso poblacional, pa. sando así de representar el 6,22\% del total de Andalucía en 1960 al 6,74\% en 1995 Este importante crecimiento demográfico, no obstante, se ha distribuido de form heterogénea en el espacio concentrándose principalmente en la zona litoral, mien. tras el interior se desertiza progresivamente (el 63,3\% de la superficie sólo acog€ al $22,3 \%$ de la población).

El crecimiento diferencial de la población almeriense desde la década de los setenta obedece a razones económicas y sociales de diversa índole: por una parte la crisis económica en esta década frenó la emigración y animó al retorno de los emigrantes; y por otra, el sistema democrático profundizó los contenidos del Es. tado del Bienestar, lo que se tradujo en mejoras de los servicios públicos y trans. ferencias, facilitando así, la retención de los almerienses en su territorio.

Pero es el fuerte crecimiento económico al que asiste la provincia a finales d $\epsilon$ los años sesenta la causa fundamental que explica el mayor dinamismo demográ. fico de Almería; crecimiento económico que, por su intensidad, ha permitido ga. nar posiciones en términos de convergencia de PIB per cápita respecto al conjun. to de provincias españolas.

En el examen detenido del comportamiento de esta variable se advierte cómc hasta 1967 Almería ocupa los últimos lugares en el ranking nacional, con una pro. ducción per cápita que apenas alcanzaba el $50 \%$ de la media española y el $75 \%$ de la andaluza, siendo a partir de ese momento cuando se produjo el gran despegue que permitió alcanzar el $75 \%$ de la media nacional y superar en cinco punto: porcentuales la andaluza en 1995. Sin embargo, el proceso de convergencia ha vistc frenado su impulso desde el comienzo de la pasada década por el mayor crecimien. to demográfico de la provincia en relación con Andalucía y España.

Si bien todos los sectores han contribuido al crecimiento económico provincial ha sido el sector agrícola el que ha soportado en mayor medida el cambio de po sición relativa de la economía almeriense. En sentido contrario a la dinámica de especialización de las sociedades industriales, el sector agrícola ha tenido un des tacado protagonismo en el crecimiento de la economía provincial, como lo prue ba que su aportación al crecimiento del PIB haya sido del 26,7 \% anual por tér mino medio (frente al 4,4\% en España), lo que le ha llevado a triplicar su aporta ción a la producción agraria nacional y a distinguirse con un índice de especiali zación agraria del 391,3. 


\begin{tabular}{lcccc}
\hline & & PIB \% (1995) & $\begin{array}{c}\text { Indice de } \\
\text { especialización* } \\
\text { (media=100) }\end{array}$ \\
\cline { 2 - 5 } & Almería & Andalucía & España & 391 \\
Agricultura y Pesca & 18,8 & 9,6 & 4,8 & 49 \\
Industria & 10,8 & 14,2 & 22,1 & 95 \\
Construcción & 7,5 & 8,6 & 7,9 & 96 \\
Servicios & 62,8 & 67,6 & 65,2 & \\
\hline
\end{tabular}

* Respecto a la media nacional.

Fuente: BBV y elaboración propia,

Como es bien sabido, esta especialización agraria se ha basado en un potente sector agrícola intensivo en producciones hortofrutícolas en invernadero, destinadas en buena parte a la exportación. Las credenciales de este sector son notables: una producción de 2.604.474 Tm en 1997 (más del triple que en 1975), que representaba el $42 \%$ de la producción andaluza del sector y el $11 \%$ de la nacional, siendo la primera provincia productora de hortalizas del país.

Notables son también algunos indicadores que dan noticia de la intensidad y de la eficiencia comparada del sector: los rendimientos por unidad de superficie son 53,5 veces superior a la media de la agricultura andaluza, 20,4 a la del olivar y 3,7 a las fresas y cítricos de Huelva; la productividad del trabajo es 1,3 mayor que la media andaluza, cerca del doble que la del olivar, y 1,5 veces superior a la de los cultivos de fresa y cítricos de Huelva; también es más intenso el uso del factor trabajo por unidad de superficie ( 50 veces, 10,7 y más del doble de los referentes anteriores) y, finalmente, es la agricultura de regadío más eficiente en el uso del agua, como lo pone de manifiesto que es 3,9 superior al resto de los regadíos en términos de $\mathrm{VAB} / \mathrm{m}^{3}$.

Un comportamiento tan singular de un sector agrícola como el referido es lógico que atraiga la curiosidad y que se indaguen en las razones que lo han hecho posible. Como tantos hechos económicos notables, el comportamiento reseñado es el fruto de la conjunción de una serie de factores en el tiempo y en el espacio, algunos suficientemente conocidos y otros, tal vez, menos valorados:

- La dotación de factores naturales.

- El descubrimiento accidental de la técnica de cultivo de los enarenados.

- Las actuaciones del Instituto Nacional de Colonización.

- Un mercado en expansión de los productos hortofrutícolas, en general, y de los de fuera de temporada en particular, en un marco de apertura comercial a Europa. 
- Una mano de obra joven y abundante, con gran capacidad de trabajo y baja aversión al riesgo, que no tenía otras alternativas más que la emigración.

- La aportación tecnológica inicial de agricultores inmigrantes con experiencia.

\section{OBJETIVO Y METODOLOGÍA}

Una vez puesta de manifiesto la importancia trascendental de la agricultura intensiva para el desarrollo económico de Almería, lo realmente trascendente es la generación en su entorno de una gran diversidad de actividades industriales y de servicios que enriquecen el sistema productivo provincial para caracterizarlo como un sistema productivo más desarrollado.

El objetivo por tanto que persigue este estudio tiene una doble vertiente:

- Profundizar en el conocimiento de las estructura de costes de las unidades de explotación agrícola, lo que nos permitirá caracterizar esta actividad agrícola de manera más precisa y cuantificar los agregados más significativos del sector,

- escrutar el sistema de interrelaciones en el sistema productivo local generado en torno a la agricultura bajo invernadero en su conjunto, analizando las potencialidades y restricciones del modelo.

El análisis input-output y la estimación de los multiplicadores son el soporte habitual del análisis económico para cuantificar la importancia de las interdependencias productivas de un sistema económico. Si se dispusiese de una tabla input-output para la provincia de Almería con suficiente nivel de desagregación podría construirse la malla de relaciones de la producción hortofrutícola y valorar los efectos multiplicadores que, aumentos o disminuciones en la producción del sector, pudiesen generar en el resto del sistema productivo. Existen tablas input-output para algunas provincias españolas, pero no para Almería, por lo que, dado el interés que este cálculo tiene para el objeto de estudio, se ha realizado una estimación tentativa de los impactos de la producción hortofrutícola en el conjunto de la economía almeriense.

Para ello se ha reunido información a partir de fuentes de distinta naturaleza, entre las que se encuentran las Tablas Input-Output de Andalucía y la Distribución Provincial de la Renta Nacional, 1993 del Banco Bilbao Vizcaya (1995); informes y estadísticas sectoriales, tales como la Encuesta Industrial de Empresas del INE, las Estadísticas Agrarias de la Consejería de Agricultura y Pesca de la Junta de Andalucía, el Boletín Estadístico del Banco de España, Anuarios de la Unión Nacional de Cooperativas de Crédito, informes anuales sobre la agricultura anda- 
luza de Unicaja, el directorio de empresas Ardán, entre otros; e informes y publicaciones de carácter provincial en relación con la comercialización de los productos hortícolas, la agricultura bajo invernadero, informes anuales de Cámara de Comercio, Industria y Navegación de Almería, etc.

Sin embargo, la información que se desprende de estas fuentes ha resultado insuficiente para caracterizar cualitativa y cuantitativamente este sistema de relaciones, tanto por su reducida desagregación sectorial y espacial, como por la falta de estudios de estructura a nivel microeconómico de las distintas actividades que intervienen. Esto ha obligado a recabar información directa, realizando un amplio número de entrevistas ${ }^{1}$ a personas relacionadas con los distintos sectores productivos. Aunque la información obtenida no goce de alta significatividad estadística, el contraste de la información del panel de expertos permite una primera aproximación para la valoración de la entidad de las actividades analizadas y de las relaciones entre ellas.

La selección de los 28 entrevistados se hizo de forma convencional a partir del conocimiento de personas cualificadas sobre cada uno de los sectores, entre los que se encontraban: gerentes de cooperativas, alhóndigas y SAT, directores de las principales empresas de cada rama de actividad, ingenieros agrónomos y técnicos agrícolas, personal especializado de la administración pública local, provincial y autonómica, directores de centros de investigación, presidentes de asociaciones empresariales y gerentes de comunidades de regantes.

Una vez realizada la explotación de los datos en primera instancia, se procedió a su contrastación sometiendo las estimaciones obtenidas al criterio de distintos especialistas relacionados con el tema hasta obtener las estimaciones con carácter definitivo.

\section{LA ESTRUCTURA DE COSTES DE LAS EXPLOTACIONES AGRARIAS}

La primera aproximación al cluster se realizó del lado de las explotaciones agrarias tratando de cuantificar las demandas de inputs productivos que éstas generaban. Esta generación de inputs no sólo hace referencia al activo circulante propio de las tareas habituales a lo largo del periodo natural de explotación, incluyendo los requerimientos propios de aquellas explotaciones que anualmente se ponen en cultivo.

1. El diseño de las entrevistas recogía aspectos relacionados tanto con las características propias de las empresas (número de trabajadores, tipo de relación contractual, destino de sus principales productos, procedencia de los consumos intermedios y bienes de capital, etc.), como sobre las apreciaciones de las magnitudes más significativas del sector y su dinámica en relación con la competencia, innovación y expectativas sobre evolución de la demanda, entre otras. 
Para ello se han estimado tanto la estructura de los costes que deben abordarse para poner en funcionamiento la explotación agrícola bajo invernadero como Ia estructura productiva de explotación anual -incluidos costes de amortización de activos-.

A continuación se presentan los resultados del estudio microeconómico realizado sobre la base de un conjunto de consideraciones técnicas susceptibles de homologar la amplia diversidad de explotaciones que se agrupan en torno a la agricultura bajo invernadero almeriense. Para ello se ha considerado una unidad productiva de $1 \mathrm{Ha}$, con una alternativa de cultivo en la que se han ponderado las distintas variedades, una estructura de invernadero metálica, que utiliza la técnica del enarenado y el sistema de riego por goteo.

Hay que advertir, no obstante, que los datos obtenidos presentan amplios coeficientes de variación en sus valores medios por varias razones:

- El precio de la tierra depende de un conjunto de variables de diferente consideración, lo que introduce notables variaciones ${ }^{2}$ según la zona.

- La alternativa de cultivo no es homogénea ni espacial, ni temporalmente, ya que las fluctuaciones de los precios en el mercado hacen que los cultivos penalizados en años anteriores reduzcan su participación en la alternativa del año siguiente. Esto hace, a su vez, que: los valores medios de los consumos en concepto de fertilizantes, semillas y fitosanitarios fluctúen por su alto grado de especificidad, afectando también a la intensidad de mano de obra, ya que el manejo de los cultivos es distinto de una variedad a otra.

- Incluso dentro de una determinada alternativa los precios medios de las semillas, los fertilizantes $y$, sobre todo, los fitosanitarios, pueden fluctuar de forma notable.

- Existe una amplia variedad de estructuras de invernadero, con dotaciones diferentes de maquinaria, sistema de riego, tipo de técnica de cultivo (enarenado, sustrato inerte, tipo de abonado), etc.

De acuerdo con estas consideraciones, y tal y como se observa en el cuadro adjunto, se puede estimar que la inversión inicial se encuentra alrededor de 137.992,38 euros por hectárea, sin incluir la adquisición del terreno, y entre 18,31 euros $/ \mathrm{m}^{2}$ y 31,82 euros $/ \mathrm{m}^{2}$ si se contabiliza éste. Estas estimaciones confirman que la agricultura bajo invernadero es muy intensiva en capital con relación a otras formas de producción agrícola.

2. Estas variaciones, en algunos casos del $400 \%$, introducen fuertes distorsiones en el análisis de la estructura de costes, de modo que se ha decidido aislar este efecto presentando el intervalo de valores medios en función de la variación máxima que presenta esta partida por zonas y de la necesidad de adquirir el terreno. Así, en el escenario 1 se adopta la hipótesis de que el agricultor ya dispone del terreno; en el escenario 2 se supone que el precio de la tierra alcaoza un valor cercano a 4,50 euros $/ \mathrm{m}^{2}$; tomando 18 euros $/ \mathrm{m}^{2}$ para el escenario 3 . 


\begin{tabular}{lcccc}
\hline Partidas & $\begin{array}{c}\text { Gastos } \\
\text { comunes } \\
\text { euros }\end{array}$ & $\begin{array}{c}\text { Escenario 1 } \\
\text { (terreno en } \\
\text { propiedad) } \\
\%\end{array}$ & $\begin{array}{c}\text { Escenario 2 } \\
\left(4,50 \text { euros } / \mathrm{m}^{2}\right) \\
\%\end{array}$ & $\begin{array}{c}\text { Escenario 3 } \\
\left(18 \text { euros } / \mathrm{m}^{2}\right) \\
\%\end{array}$ \\
\hline Adquisición del terreno & - & 0,0 & 24,62 & 56,65 \\
Preparación del terreno & $15.025,30$ & 10,9 & 8,21 & 4,72 \\
\hline Sustratos & $19.532,89$ & 14,2 & 10,67 & 6,14 \\
Invernadero & $71.520,44$ & 51,8 & 39,07 & 22,47 \\
Riego por goteo & $12.621,25$ & 9,1 & 6,89 & 3,97 \\
Otros & $19.282,49$ & 14,0 & 10,54 & 6,06 \\
\hline Total inversión inicial (euros) & - & $\mathbf{1 3 7 . 9 9 2 , 3 8}$ & $\mathbf{1 8 3 . 0 6 8 , 2 9}$ & $\mathbf{3 1 8 . 2 9 6 , 0 1}$ \\
\hline
\end{tabular}

Fuente: Elaboración propia.

Asimismo, la estructura de inversión inicial da noticia de las importantes vinculaciones que este tipo de agricultura establece con otras actividades de su entorno como construcción, plásticos, construcción de invernaderos, etc. Por componentes, cabe destacar el peso que presenta la estructura de invernadero con un $58 \%$ de los costes totales mientras que el aporte de sustrato alcanza el 14,2\%.

Para el análisis y estimación de los costes variables de explotación a lo largo de una campaña se han tenido en consideración las partidas que se detallan en el cuadro adjunto. Este cuadro no sólo incorpora los gastos corrientes propiamente dichos sino también las dotaciones anuales en concepto de amortización, que deben recoger las cuentas de la explotación para hacer frente a la renovación futura del inmovilizado. Así, en la segunda columna se recogen los pesos relativos de los costes variables y de los gastos de amortización de manera separada, mientras que la tercera muestra la importancia de los gastos globales una vez incorporada la amortización a la estructura de costes.

A la vista de los datos de estructura podemos hacer las siguientes observaciones:

1. Existe una gran intensidad de relaciones con otras ramas de la economía tanto industriales como de servicios. Este proceso de externalización de funciones se ha ido intensificando a lo largo del tiempo, así en la actualidad existen empresas que se dedican a la limpieza de invernaderos, al mantenimiento de estructuras y a la germinación de semillas. Esta división del trabajo, como es obvio se ha traducido en una mayor especialización por funciones y ha permitido la generación de externalidades tanto estáticas como dinámicas. 
GASTOS ANUALES

\begin{tabular}{|c|c|c|c|}
\hline Gastos corrientes & Euros & $\begin{array}{l}\% \text { Gastos } \\
\text { corrientes }\end{array}$ & $\begin{array}{c}\text { \% Gastos } \\
\text { anuales }\end{array}$ \\
\hline Mano de obra & $14.256,01$ & 42,3 & 33,3 \\
\hline Semillas y plantones & $5.409,11$ & 16,1 & 12,6 \\
\hline Agua & 967,63 & 2,9 & 2,3 \\
\hline Agroquímicos & $5.108,60$ & 15,2 & 11,9 \\
\hline Energía & 420,71 & 1,2 & 1,0 \\
\hline Servicios & $7.512,65$ & 22,3 & 17,5 \\
\hline Total gastos corrientes & $33.674,71$ & 100,0 & 78,6 \\
\hline Gastos de amortización & Euros & $\begin{array}{c}\% \text { Gastos } \\
\text { anualizables }\end{array}$ & $\begin{array}{c}\% \text { Gastos } \\
\text { anuales }\end{array}$ \\
\hline Aporte de estiércol & 601,01 & 6,6 & 1,4 \\
\hline Estructuras de invernaderos & $3.503,90$ & 38,3 & 8,2 \\
\hline Plástico & $2.479,17$ & 27,1 & 5,8 \\
\hline Grupo motobomba y cabezal & 751,27 & 8,2 & 1,8 \\
\hline Red de riego & 826,39 & 9,0 & 1,9 \\
\hline Balsa de riego & 383,45 & 4,2 & 0,9 \\
\hline Equipamiento & 601,01 & 6,6 & 1,4 \\
\hline Total gastos de amortización & $9.146,20$ & 100,0 & 21,4 \\
\hline TOTAL GASTOS ANUALES & $42.820,91$ & - & 100,0 \\
\hline
\end{tabular}

Fuente: Elaboración propia.

2. La mano de obra tiene un lugar destacado en la estructura de costes $(42,3 \%)$ poniendo de manifiesto otro rasgo característico de la agricultura bajo invernadero de Almería: su intensidad en el uso del factor trabajo. Intensidad que se hace máxima en el monocultivo de tomate donde esta partida puede llegar a alcanzar 3,70 euros $/ \mathrm{m}^{2}$.

3. Los componentes incorporan un alto grado de innovación. La mayor parte de los inputs productivos de los que hace uso la explotación agrícola como plásticos, sistemas de riego, fertilizantes, semillas y plantones, etc., han desarrollado complejas rutas de innovación que han redundado en importantes ganancias de productividad y calidad. 
4. El uso intensivo de los fertilizantes y fitosanitarios en el enarenado hay que entenderlo en el marco de la naturaleza de la actividad productiva, sin embargo, soporta un peso desmesurado. La tendencias del mercado hacia alimentos más saludables y el estrechamiento de los márgenes de explotación deben obligar a un uso más racional de los mismos, promoviendo buenas prácticas agrícolas que eviten la propagación de enfermedades y la reutilización de los nutrientes.

5. El precio del agua pagado por los agricultores, no corresponde, como es sabido, a un precio de mercado sino al coste de extracción por parte de las comunidades de regantes. No obstante, el principal problema de este recurso no es el precio sino su calidad y disponibilidad, ya que por ejemplo, un aumento en el precio del metro cúbico del agua de un $200 \%$-equivalente a 0,41 euros $/ \mathrm{m}^{2}$, que es el precio estimado de abastecimiento de una central desaladora- apenas supondría un incremento del $6 \%$ sobre el cómputo global de los gastos corrientes.

En conjunto se puede afirmar que los gastos de explotación por una unidad de producción tipo se aproximan a 3,37 euros $/ \mathrm{m}^{2}$ en cómputo anual. Si a esto añadimos la provisión en concepto de amortización de aquellos activos fijos que, bien por desgaste, bien por obsolescencia, deben ser restituidos, los costes que debe asumir la explotación ascenderían a 4,28 euros $/ \mathrm{m}^{2}$ al año.

A partir de los datos que aquí se presentan se han llevado a cabo distintas estimaciones de las demandas de productos industriales y de servicios por parte de las explotaciones agrarias, y de la producción agregada a partir de la estructura de costes de las unidades productivas.

La demanda de consumos intermedios y de bienes de capital recoge tres componentes diferenciados:

- Cada año se ponen en cultivo del orden de 1.500 ha. lo que supone una expansión de demanda de bienes de inversión por valor de 196,17 millones de euros.

- Pero, además de la satisfacción de la demanda derivada de los gastos de inversión necesarios para posibilitar la expansión de superficie invemada, a lo largo del año gran número de las explotaciones, ya existentes, adquieren y mejoran su activo fijo, incrementando así, la demanda de aquellas empresas suministradoras de sistemas de riego, abono, estructuras de invernadero o plásticos.

- Finalmente, a esto hay que añadir las demandas de inputs intermedios de las explotaciones en cultivo para llevar a cabo su actividad productiva. 
Así pues, la demanda final de las explotaciones que se encontraban en cultiv en 1998 fue de 609,92 millones de euros, lo que sumado a los requerimientos prc pios de las inversiones en inmovilizado de las explotaciones de nueva creaciór da una demanda total de 805,49 millones de euros.

Asimismo, se ha realizado una estimación del valor de la producción agregad a partir de la estructura de coste para una explotación tipo de 1 ha. presentada lo largo de este capítulo. Para ello se ha hecho el supuesto adicional de que la explotaciones alcanzan una rentabilidad, por término medio, de un $20 \%$ sobre 1 producción final, dato que resulta del panel de expertos consultados.

El valor de la producción para el conjunto de la agricultura intensiva almeriens sería de 1.575,65 millones de euros lo que supone un ingreso medio por hectárea d en torno a 59.091,09 euros, de los que 25.242,51 corresponden a valor añadidc

\section{ESTIMACIÓN DE LA PRODUCCIÓN}

\begin{tabular}{lccr}
\hline & \multicolumn{2}{c}{ Millones de Euros } & \\
\cline { 2 - 3 } Total & \multicolumn{2}{c}{ Ha. } & $\%$ \\
\hline Gastos de explotación* & 728,23 & 4,17 & 46,2 \\
Gastos financieros & 113,29 & 0,65 & 7,2 \\
Gastos de personal (1) & 413,42 & 2,37 & 26,3 \\
EBE (2) & 319,74 & 1,83 & 20,0 \\
VAB (1+2) & 733,16 & 4,20 & 46,6 \\
Producción & $1.574,65$ & 9,03 & 100,0 \\
\hline
\end{tabular}

Elaboración propia.

* Excluye los gastos de personal.

Estas estimaciones presentan sensibles divergencias con las realizadas por li Consejería de Agricultura y Pesca para 1997, ya que suponen un crecimiento de valor de la producción en un 48\% para el periodo 1997-1998 cosa del todo injus. tificable por fundamentos; sin embargo, esta estimación está notablement infravalorada como demuestra también la Encuesta sobre Regadíos de Andalucíc para 1996. Esta fuente estima el valor de la producción en 1.322,23 millones pará 1996. Teniendo en cuenta que para ese año la producción de frutas y hortalizas bajo invernadero alcanzaba el 93,9\% del total de la producción final agrícola de Almería, el valor de la producción en invernadero sería de $1.241,57$ millones de euros, de modo que para alcanzar en 1998 los 1.575,65 millones de pesetas correspondiente a la estimación propia debería haber crecido a una tasa anua: acumulativa en torno al $12 \%$, lo que corresponde con el crecimiento estimado por la Consejería de Agricultura para el periodo 1996-98. 


\section{INDUSTRIA Y SERVICIOS AUXILIARES}

Como venimos diciendo la trascendencia de la agricultura intensiva para Almería no se agota en la estricta producción agrícola, sino que, al calor de este sector, ha ido surgiendo un conjunto de actividades industriales y de servicios que están enriqueciendo el sistema productivo.

En el gráfico de la página siguiente se representa el complejo entramado de relaciones que tienen como origen primario la agricultura intensiva. Como puede observarse, el «cluster» de actividades es muy complejo, incluyendo tanto actividades industriales como de servicios, que se vinculan con la agricultura intensiva de forma directa (en muchos casos, exclusiva) abasteciéndola de inputs intermedios o complementando la cadena de valor.

A continuación haremos un breve repaso de cada una de ellas deteniéndonos especialmente en aquellas que juegan un papel relevante en el proceso de generación de externalidades, sino en el presente, con vocación de futuro si llegan a desarrollarse las políticas de fomento adecuadas.

\subsection{El sistema de comercialización}

El intenso desarrollo experimentado por la agricultura intensiva de Almería no podría entenderse sin dar cuenta de un sistema de comercialización que ha permitido colocar en los distintos mercados, con mayor o menor dificultad a lo largo de los años, la producción hortícola.

El moderno sistema de distribución con el que cuenta Almería actualmente es el resultado de una larga evolución histórica orientada a dar solución a una serie de problemas que amenazaban, allá por los años 60 , el crecimiento de la agricultura provincial. La falta de concentración de la oferta en las explotaciones agrícolas, el desconocimiento de los precios, la carencia de información sobre los canales de comercialización y la ausencia de disciplina en la obtención estándares de calidad, colocaba a los agricultores en una posición muy vulnerable, a la vez que permitía a empresarios de otras provincias, con mayor tradición comercial, apropiarse del valor añadido derivado de las labores de manipulación y dominar los canales de distribución.

Esta evolución ha cristalizado en una configuración bien distinta de la que presentaba en sus orígenes, no respondiendo a un único modelo sino a una heterogeneidad de modalidades de manipulación y comercialización, lo que sin duda es un acicate enriquecedor. Entre los agentes que forman el sistema de comercialización destacan de forma notable las alhóndigas, o centros de distribución en origen ${ }^{3}$, y

3. La venta de los productos se realiza mediante subasta a la baja, con la posibilidad por parte del agricultor de retirar su producción en el caso de que no se satisfagan sus expectativas de precios finales 
las agrupaciones de agricultores especializadas en la venta de producción en des tino. Junto a estas dos figuras también participan buen número de agentes a ac túan de intermediarios de la mercancía tanto en origen como en destino.

Las alhóndigas han jugado un papel de indiscutible importancia en el desarrc llo del sistema de comercialización de la producción hortícola provincial. Este pape no se ha restringido únicamente al desempeño de tareas comerciales, ejerciend funciones de financiación al facilitar liquidez, en forma de suministros, a las ex plotaciones agrarias y al asumir los riesgos de impago de los clientes, una vez qu el agricultor recibe su dinero.

Interrelaciones productivas del cluster.

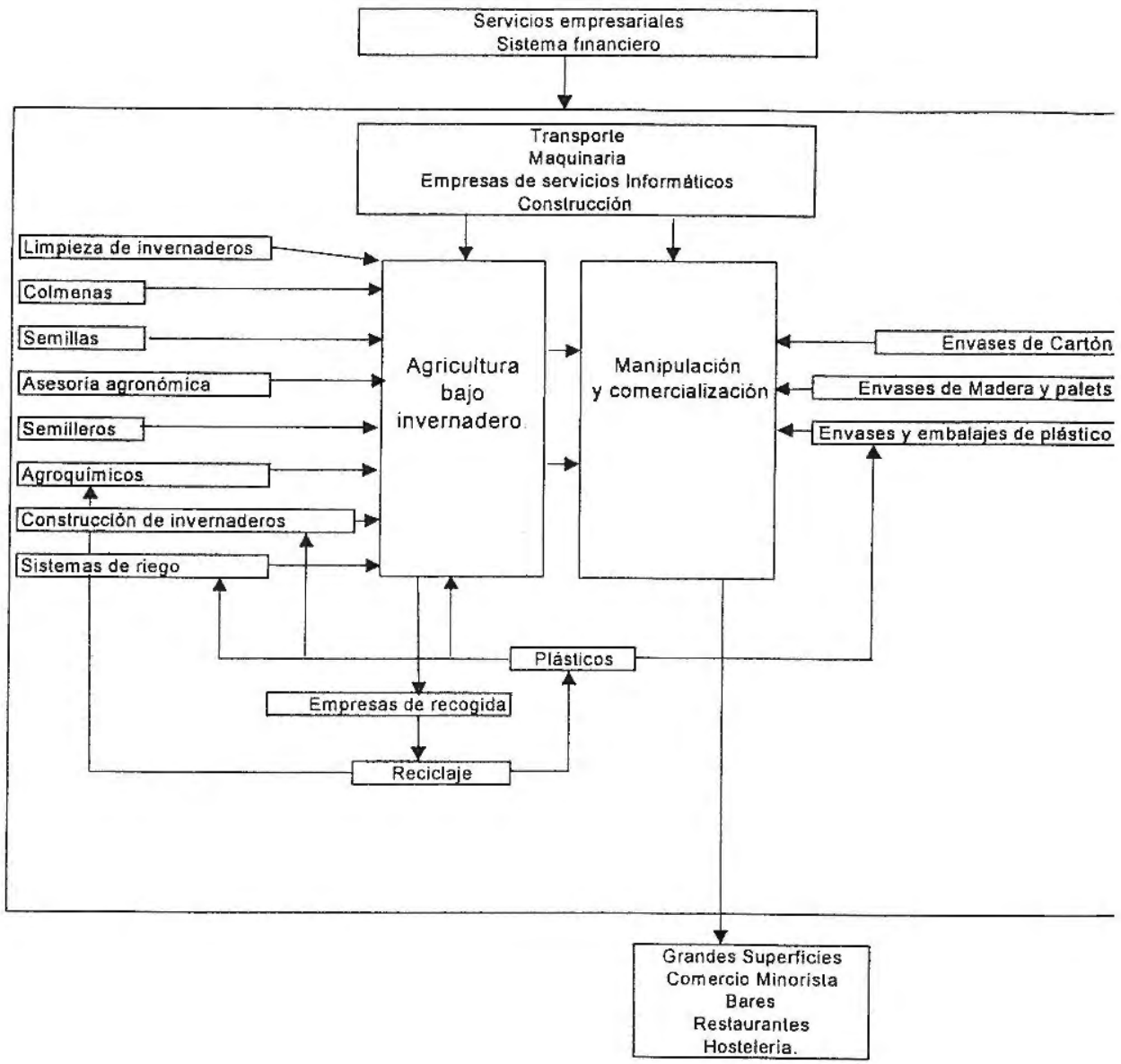

Fuente: Elaboración propia. 
Con el paso del tiempo el peso de las alhóndigas ha ido descendiendo progresivamente en favor de las agrupaciones de agricultores pasando de una cuota de gestión de mercancía del 75\%, al final de los años ochenta, hasta alcanzar el 50\% que se conoce hoy. El número de empresas en 1998 era de 25, concentrando entre las 7 mayores el $55 \%$ de la facturación. El tamaño es muy variable conviviendo empresas con varios centros de trabajo, con otras que comparten una misma instalación. Por término medio, estas empresas incorporan alrededor de un 9,5\% de valor añadido sobre la producción que comercializan, experimentando una pérdida progresiva de empleo a lo largo de los últimos 5 años, explicable fundamentalmente por la incorporación de tecnologías de proceso.

A mediados de los años 80 , primero con carácter de intervención sobre el precio de subasta y posteriormente de una manera permanente, estas empresas han ido asumiendo, con mayor o menor intensidad, tareas de manipulación y venta en destino de parte de la producción que comercializaban.

Las agrupaciones de agricultores, por su parte, se articulan en tomo a figuras fundamentalmente asociativas tales como cooperativas y sociedades agrarias de transformación (SAT), aunque también existen sociedades mercantiles de escasa importancia en el sector. Estas figuras asociativas prestan servicios de comercialización, abastecimiento de suministros y asistencia técnica a sus socios, estableciendo estrechos vínculos de colaboración que permiten realizar un estricto seguimiento de la producción agrícola.

El número de entidades que conforman el sector era de aproximadamente 60 . Aunque el valor añadido que generan se aproxima al $12 \%$ sobre el volumen de producción que comercializan, duplicando el gasto de personal por kilogramo distribuido que se observa en las alhóndigas, esta cifra ha sufrido un estancamiento en su evolución alcista gracias a la progresiva incorporación de maquinaria en tareas que antes demandaban mayores requerimientos de mano de obra. A primera vista, conociendo la correlación positiva entre las labores de manipulación en las que se especializan la agrupaciones de agricultores y el valor añadido, no parece que un $12 \%$ quede muy lejos del $9 \%$ que presentan las alhóndigas. Para entender esto hay que hacer una apreciación adicional que tiene que ver con la distinta naturaleza de las figuras societarias que operan en cada sector y con el reparto de beneficio final de las operaciones mercantiles, ya que, si bien en el caso de las alhódigas el excedente bruto de explotación es un componente de cierta consideración dentro del VAB, esta partida no existe en la sociedades cooperativa y SAT donde las ganancias de la sociedad se reparten entre los socios en forma de precios más elevados y gastos por suministros más reducidos.

Una vez que la producción abandona los centros de comercialización es intervenida en parte por agentes de comercialización tales como distribuidores y mayoristas, dotados en su mayoría de instalaciones equipadas para almacenar y manipular la mercancía antes de ser enviada definitivamente a su destino final. 
También hay una parte, ciertamente marginal (3\%) que se canaliza a través d agentes intermediarios -sin infraestructura comercial-y que actúan comprando po cuenta de terceros y enviando la mercancía directamente a su cliente.

Las características más relevantes del sector pueden resumirse como sigue

- La generación de valor añadido no se distribuye homogéneamente entre lo participantes, existiendo variaciones de cierta importancia en función de grado de manipulación de producto que realice la empresa.

- El empleo es básicamente nacional -el número de inmigrantes contratado por las empresas comercializados para la realización de tareas de manipu lación es marginal- y se caracteriza por un alto grado de temporalidad observándose puntas de contratación en marzo, abril, noviembre y diciem bre, coincidiendo, como es obvio, con las épocas de más intensa recolec ción.

- Al margen de la presencia testimonial de agentes foráneos que comerciali zan sus propias producciones -generalmente ingleses- el capital invertidc en las empresas comercializadoras es de titularidad provincial.

- Por término medio, se observa un exceso de capacidad productiva instala da de en torno al $30 \%$ lo que se explica por la alta estacionalidad que pre. senta la producción hortícola.

- Por lo general, las empresas prestan servicios gratuitos a sus socios y clien. tes, de carácter fundamentalmente técnico-agronómico, proporcionándoles también envases de campo en régimen de depósito. En la mayoría de los casos, los servicios técnicos tienen una clara finalidad de control a pie d $\epsilon$ explotación, garantizando así la calidad del producto final.

- El sistema de comercialización, por otra parte, se configura como un destino muy importante de consumos intermedios de diversa naturaleza, entre los que cabe mencionar: envases de cartón y plástico, accesorios y film de embalaje (alvéolos, flow pack...), palets de madera y plástico, maquinaric de clasificación, envasado, transporte interno, cámaras frigoríficas, etc.. aparte de la principal partida en el capítulo de compras, su materia prima básica: la producción hortícola.

- Existe un alto grado de heterogeneidad en el origen de los aprovisionamientos industriales ya que las variables que inducen a la compra de un determinado insumo no se corresponden únicamente con la cercanía $\mathrm{c}$ el precio, justificándose en muchos casos por la inexistencia del productc en la provincia, la tradición, o la política de diversificación de proveedores. No obstante, los eslabonamientos que genera la actividad comercial tie- 
nen fuertes efectos -en términos de renta y empleo- sobre el conjunto del cluster ya que muchas empresas -fundamentalmente de sectores tales como envases y embalajes de cartón y plástico, maquinaria y transporte- se han constituido para satisfacer las demandas de consumos intermedios de las empresas de manipulación y comercialización.

- A lo largo del tiempo las empresas han venido experimentando una profunda transformación tanto en los procesos de gestión administrativo-comercial -adoptando avanzados sistemas de gestión empresarial y marketing-como en los relacionados con las labores de manipulación de la mercancía. Así, poco a poco estas empresas han ido introduciéndose en modelos capital intensivos, mecanizando fases de producción tales como la clasificación (por tamaño y color), el flejado, el transporte interno de mercancías, etc. Este proceso está todavía inacabado, no tanto porque no se haya llegado a una mecanización completa de las líneas de manipulación a través de la incorporación de automatismos y robots, como porque aún existe buena parte de la producción que no se somete a tareas de tipificación y normalización.

El interés por llegar a la completa normalización de los productos que se comercializan se justifica porque su adopción introduce un sistema de incentivos que remunera más al que más se esfuerza por conseguir una producción de calidad. La normalización puede llevarse a cabo por el agricultor en primera instancia -como en los Países Bajos- o por la comercializadora. Este proceso de transformación no está exento de dificultad, tanto por el enorme esfuerzo inversor que han de acometer las empresas en inmovilizado, como por el cambio de cultura que debe operar en las explotaciones agrarias. No obstante, la normalización de la producción puede llegar a ser -como así ocurre en algunas comercializadoras- un factor de atracción de producciones desde otros espacios, reforzando las ventajas competitivas del modelo almeriense, asociadas a la consolidación de la red de distribución desarrollada ya por la producción provincial.

Por último, hay que señalar un aspecto que guarda relación con la atomización de la oferta y el poder de negociación. La falta de concentración de la oferta en origen se presenta como un problema de envergadura dado el escaso poder de negociación de muchas empresas comercializadoras; sin embargo, parece existir un nivel máximo de gestión de mercancía a partir del cual las empresas penetran en zonas de graves ineficiencias productivas, por lo que sería recomendable cierto grado de concentración, a través de la implementación de figuras asociativas que operen como una sola voz en los mercados frente a una demanda cada vez más concentrada, mientras que en el ámbito de las actividades que desarrollan las empresas en su calidad de procesadoras -entiéndase manipuladoras o simplemente gestoras de mercancía- esta concentración no es tan importante. 


\subsection{La industria auxiliar}

\section{Maquinaria}

El sector de maquinaria vinculado al cluster concentra su actividad en el abas tecimiento de dos tipos de productos con especificaciones diferentes según sea $e$ destinatario al que se dirige: la maquinaria que se dedica al manejo de las produc ciones hortícolas y semilleros y la utilizada por los centros de manipulación comercialización.

La empresas que pertenecen a este sector son de tamaño pequeño y medianc muy diversificadas y dedicadas casi de forma exclusiva a la distribución. Ademá de comercializar marcas de maquinaria fabricadas fuera de la provincia, tambié distribuyen envases y embalajes, y disponen de talleres de mantenimiento y repa ración.

El capital invertido es de titularidad provincial, síntoma inequívoco del conti nuo proceso de capitalización generado a partir de las rentas derivadas de la pro ducción agrícola, sin embargo, su origen es variado, ya que, aunque algunas de ella: han surgido de actividades afines a la agricultura de forzados otras se han incorpo rado desde sectores como la refrigeración, maquinaria para la construcción, etc

En cuanto a la proyección extraprovincial, ésta se circunscribe a pequeñas in cursiones en Latinoamérica o el norte de África, no alcanzando valores significa. tivos en ningún caso, lo que se explica básicamente por su papel de distribuidora: en el mercado local.

La innovación tecnológica de las empresas almerienses del sector es muy re. ducida, concentrándose en las que, en colaboración con entidades públicas, desa. rrollan proyectos de investigación centrados en la resolución de problemas concretos (fundamentalmente adaptaciones) financiados parcialmente a través de subvenciones de la UE.

La inexistencia de fabricación de maquinaria en la provincia viene explicad por razones de diversa índole, entre las que cabe destacar: la importante inversiór. a realizar en unas líneas de producción con amplias economías de escala y de gama: falta de tradición industrial que se traduce en desconocimiento de las tareas de producción, de la tecnología necesaria y de los mercados de destino; la escasa implantación de empresas satélites especializadas en mecanización, automatización. robotización, electrónica, visión artificial, software industrial, etc.; la fuerte competencia de grandes grupos empresariales consolidados a escala internacional, que condicionan gran parte de su crecimiento a la posesión de tecnología a través de alianzas empresariales y conglomerados industriales; y, por último, la falta de incentivos para acometer una actividad tan arriesgada cuando, al menos hasta el momento, la actividad de distribución de las empresas instaladas genera un volumen de beneficios suficiente. 


\section{Semillas}

El sector de semillas ha jugado un papel de gran importancia en el proceso de consolidación del liderazgo de la producción hortícola almeriense, ya que el modelo de producción provincial y su localización en relación con los mercados de destino, han ido forzando a las empresas vinculadas al sector a investigar continuamente para ofrecer variedades de producto que compensaran las caídas de precios con incrementos de productividad, permitieran expandir la gama de productos hortofrutícolas y mantuvieran sus cualidades organolépticas a pesar de los grandes desplazamientos a los que se ven sometidos.

Esta importancia, sin embargo, no se ha traducido en el desarrollo de una producción autóctona. Esto se explica por la propia naturaleza de su proceso productivo -se requieren líneas de investigación con periodos de maduración de hasta 8 años y presupuestos en $\mathrm{I}+\mathrm{D}$ que pocas empresas están dispuestas asumir- y por la estructura del mercado en el que se inserta. En la actualidad este mercado está dominado por empresas de gran tamaño de alcance multinacional con amplias economías de gama.

Aunque la fabricación de las semillas no se acometa en Almería las especificidad de las semillas obliga a situar los centros de investigación en la provincia que sí establecen vínculos comerciales con otras empresas provinciales en la puesta en marcha y mantenimiento de los invernaderos donde se realizan las experimentaciones. No obstante, esta demanda genera eslabonamientos interindustriales de muy baja intensidad por suponer un escaso peso relativo en la facturación de las empresas.

Llama la atención que, a pesar del carácter central que tienen las semillas para la agricultura bajo invernadero, tanto por el peso que presentan en la estructura de costes de las explotaciones agrícolas como por su insustituibilidad en el proceso productivo, sólo hayan existido en algunos momentos puntuales colaboraciones del capital almeriense en el desarrollo de alguna variedad hortícola.

\section{Sistemas de riego}

La transición que se inició al final de los años setenta y que supuso el paso del tradicional riego a pie al riego por goteo marcó el comienzo de la creación de empresas especializadas en la fabricación e instalación de los distintos elementos que forman el sistema de riego tal y como se conoce en la actualidad.

El sector está formado por alrededor de 10 empresas de cierta entidad, que fabrican buena parte de los productos que facturan -hasta un $60 \%-$, junto a más de cien instaladores que en la mayoría de los casos trabajan de manera irregular. La fabricación abarca desde el montaje de los módulos de fertirrigación, hasta el 
diseño del software de control informatizado de riego, pasando por la producció de la tubería, los portagoteros y los emisores.

Estas empresas, mayoritariamente de capital provincial, han optado por dive sificar su negocio a través de dos vías: la comercialización de automatismos dispositivos de control activo del clima y la ampliación de la gama de productc desarrollando, por ejemplo, sistemas de riego subterráneos compatibles con labc reos propios de la agricultura extensiva como el arado o la quema de rastrojo. Est último, en términos de demanda, ha supuesto un relanzamiento del sector haci otros segmentos de mercado que complementan una demanda provincial que de notaba cierto estancamiento. No obstante, es conveniente señalar que las expect $\varepsilon$ tivas creadas por la aprobación de las obras hidráulicas han hecho que al igual qu para otros sectores, la demanda de insumos intermedios para la agricultura conozc de nuevo una fase de expansión.

Para valorar las vinculaciones interindustriales entre el sector y el cluster, e preciso distinguir entre las empresas que fabrican la mayor parte de lo que factv ran, importando desde fuera de Almería los consumos intermedios que necesita -mostrando poca capacidad de arrastre sobre el conjunto del sistema-, y lo instaladores que compran tanto a empresas implantadas en la provincia como foráneas, con mayores eslabonamientos intersectoriales, pero con menor capaci dad para generar valor añadido.

En cuanto a la expansión extraprovincial de las empresas del sector, merec destacarse las incursiones realizadas por alguna de ellas en otros mercados tant nacionales como internacionales. Así, a pesar de que la expansión natural parec que se dirige hacia Murcia, Motril y Jaén, actualmente se están montando instala ciones -llave en mano- en México, y se distribuyen sistemas en Sudamérica EE.UU. No obstante, aunque alguna empresa tiene instalaciones permauentes e América Latina, esta experiencia internacional tiene, por lo general, carácter es porádico, ya que existe la opinión generalizada de que en determinados países e muy arriesgado hacer negocios por la carencia de un marco social e institucionc estable.

Las empresas de mayor entidad dedican hasta un $5 \%$ de sus gastos anuales tareas de $\mathrm{I}+\mathrm{D}$, desarrollando equipos cada vez más innovadores y eficientes. $\mathrm{E}$ la actualidad las líneas de investigación se dirigen fundamentalmente hacia el de sarrollo de programas de gestión, que permitan introducir el telecontrol de lo parámetros del sistema a través de internet y el análisis experimental de sistema de riego a distinta altura, entre otras.

Dentro de esta dinámica de innovación, el diseño del software para los módu los de fertirrigación y los desarrollos de tecnología aplicada a especificacione propias de la zona (mezcladores de agua con diferente coeficiente dieléctrico. supone atesorar activos intangibles de gran valor, no tanto por la entidad de s contribución actual a la producción provincial como por el establecimiento de un 
sólida base que permita posteriores proyecciones industriales. Si a esto unimos que su situación de cercanía permite soportar menores costes, tanto de transporte como de comercialización, reaccionar con mayor celeridad ante cambios de la demanda y detectar más fácilmente los requerimientos específicos de la zona, se tiene un sector perfectamente capaz de competir con aquellos países centroeuropeos que disfrutan de una tradición industrial más dilatada.

\section{Plásticos}

El plástico forma parte de una manera indisoluble del modelo de agricultura que se ha adoptado en Almería. Desde el film que recubre las estructuras metálicas, hasta las cajas en las que se transportan los productos hortícolas, pasando por los hilos utilizados para tutorar la planta, las tuberías, las balsas y la red de riego, tienen al plástico como componente constitutivo, dando lugar a un mercado de productos que ha ido generando a lo largo del tiempo un importante núcleo de empresas dedicadas a su fabricación y distribución.

En Almería se encuentran ubicadas - concentradas en los municipios de El Ejido y La Mojonera- alrededor de 15 empresas que se dedican a la producción de plásticos, de las cuales cuatro -3 de cierta entidad más una de pequeña dimensiónse dedican a la fabricación de film, tres concentran su actividad en la producción de envases, y el resto fabrica productos tales como rafia, riegos, y accesorios. Junto a éstas hay un número indeterminado de empresas que se dedican a la comercialización de productos fabricados fuera de Almería.

En su mayoría se trata de empresas de capital almeriense, aunque también las hay procedentes de Valencia y Murcia. Por lo general presentan líneas de producción sobredimensionadas, lo que les obliga a trabajar por encima del mínimo de sus costes medios. Si a esto unimos un cierto estancamiento de la demanda provincial en los últimos años y un aumento de las importaciones desde el mercado nacional se comprende que la diversificación de su producción (como la fabricación de contenedores para cosmética, limpieza,...), sea una estrategia común para salvar los continuos estrechamientos de márgenes de rentabilidad que han venido a situarse en torno del $5 \%$. Por otra parte, cabe destacar que disponen de eficientes instalaciones de producción, con métodos de gestión muy avanzados y con un excelente ajuste a los requerimientos de la demanda.

En cuanto a las relaciones que establece este sector con el resto de las actividades que forman el cluster, se observa una enorme debilidad en sus eslabonamientos de arrastre, en la medida en que la mayoría de los inputs intermedios demandados para la fabricación de productos plásticos -fundamentalmente la granza- no proceden de la provincia, siendo controlados por un grupo reducido de productores. No obstante, algunas de las empresas que operan en el mercado 
utilizan como materia prima los residuos plásticos generados en las unidades d producción agrícola -films, botes de fertilizantes, fitosanitarios, envases de campo, tuberías, etc.- para fabricar envases de plástico. La maquinaria utilizada en los procesos de producción es de origen fundamentalmente alemán e italiano.

La exportación del sector es un capítulo que cada vez va cobrando más importancia en virtud del alto grado de competencia en el mercado local, estimándose que el $35 \%$ de la facturación corresponde a exportación directa de productos hacia destinos tales como Murcia, Huelva y Granada dentro del mercado nacional. y México, Canadá, Francia, Chile, Argentina y Portugal en el internacional.

Otro tipo de consideraciones vinculadas al análisis del mercado local tiene que ver con la existencia de barreras a la entrada de potenciales competidores y la dinámica de los agentes frontera. En relación con lo primero merece la pena resaltar las bajas barreras de entrada, tanto de carácter tecnológico (dado que la función de producción es bien conocida no existiendo diferencias apreciables en costes), como de capital o de comercialización. En segundo lugar, tal y como se desprende del análisis realizado por el Instituto de Fomento de Andalucía (1995), los agentes frontera -proveedores y clientes- ejercen una presión muy elevada sobre los márgenes de rentabilidad, ya que por una parte el carácter oligopolístico del mercado de materias primas coloca a las empresas en una posición muy débil a la hora de negociar los términos de su adquisición, cuando además la producción de productos plásticos para la agricultura representa una fracción muy reducida de la producción total del sector; mientras que frente a los clientes, la indiferenciación de los productos finales, el poco peso que supone el plástico en la estructura de costes de las explotaciones agrícolas y la buena información disponible -sobre productos y precios- obliga a desarrollar una estrategia de competencia básicamente vía precios.

\section{Envases de cartón}

El envase de cartón ondulado es el más utilizado actualmente en el sector de comercialización hortícola por varias razones: pesa menos, es más fácil de reciclar, ha mejorado su resistencia y permeabilidad, el precio es muy competitivo y se ha adoptado la normalización ajustada al estándar europeo de paletización (Norma Platform de AFCO); lo que le ha permitido ir ganando cuota de mercado frente a su sustitutivo más directo -el envase de madera- de forma progresiva en los últimos 10 años, llegando a acaparar el $70 \%$ del mercado. No obstante, el envase de plástico se presenta como un duro competidor por su transparencia, limpieza, reutilización y por cumplir las exigencias sobre normativa medioambiental de los países centroeuropeos. 
Almería cuenta con cuatro centros de fabricación de cajas de cartón ondulado y con alrededor de 15 delegaciones de venta y puntos de montaje de cajas fabricadas en otros puntos de la geografía nacional, situándose a la cabeza del consumo de envases de cartón para frutas y hortalizas a escala nacional -con un $40 \%-$ e incluso europea.

Son empresas que dirigen su producción en un $80 \%$ al abastecimiento de cajas para la comercialización de hortalizas y frutas, siendo proveedores también de contenedores de cartón para otros sectores productivos. Las empresas fabricantes, por su parte están muy integradas verticalmente hacia delante ya que el cartón que producen es manipulado por ellas mismas hasta llegar a la caja terminada e impresa.

Aunque en Almería estas empresas no realizan actividades de I+D por tratarse de compañías multinacionales que concentran sus laboratorios en las casas matrices, la tecnología que han venido incorporando en los productos que comercializan ha permitido obtener envases cada vez más adaptados a la manipulación y transporte, mostrando una mayor resistencia a la compresión vertical, lo que permite soportar trayectos a gran distancia en pilas de mayor altura; y más capacidad para absorber la humedad que emiten los productos, contribuyendo así al mantenimiento de su calidad. Por otra parte, la constante innovación en tecnología de proceso - por parte de las empresas fabricantes de maquinaria- ha permitido la adopción de automatismos en las líneas de producción, haciendo que etapas que antes se realizaban de forma manual, sean menos intensivas en trabajo, consiguiéndose así, considerables ganancias de productividad.

Por lo general, la capacidad de arrastre de esta actividad sobre el tejido productivo es muy débil, ya que, por una parte, las empresas que centran su negocio en la distribución de cajas que importan desde otros espacios, como es lógico, no establecen interrelaciones industriales con el resto del cluster que no sean de carácter general como asesoría legal, transportes, etc.; y por otra, las empresas fabricantes, al margen de las adquisiciones que realizan en la provincia de tinta para la impresión y sosa, que apenas supone un 5\% de los costes en materias primas, también importan la materia prima que necesitan para sus procesos de producción. Así pues, el papel y el almidón proceden de Castilla, Extremadura y Portugal dentro de la península, importándose también desde EE.UU., Sudáfrica, Canadá y países nórdicos; la maquinaria se importa en su práctica totalidad de Alemania, abasteciéndose de utillaje en el mercado regional o nacional, aunque esta partida tampoco tiene un peso muy significativo en la estructura de costes.

\section{Madera y sus derivados}

En Almería este sector ha venido abasteciendo la demanda de tres productos del cluster: envases, palets y postes para invernadero. El sector en su conjunto ha 
sufrido una progresiva pérdida de peso a lo largo del tiempo por la introducción de otras materias primas sustitutivas, como el plástico, el cartón ondulado y el acero galvanizado.

Tradicionalmente el envasado de la producción hortícola se realizaba en cajas de madera; sin embargo, el envase de cartón ondulado en un primer momento y posteriormente el plástico, han obligado a la madera a ceder posiciones hasta significar menos del $1 \%$ del mercado, sumiéndose en una dinámica de transformación, más cercana a la lucha por la supervivencia, que a una reconversión en sentido estricto, ya que no se acometieron en su momento las inversiones necesarias en mecanización e innovación que hubieran permitido mejorar su competitividad en precio, calidad y diversificación de producto.

En la actualidad existen empresas muy tecnificadas con cadenas de producción robotizadas que dirigen sus líneas de diversificación de producto hacia una mayor especialización en envases de pequeña capacidad para productos de gama alta, aprovechando la asociación que existe entre la madera y marcas de calidad.

Por su parte, el segmento de palets, mantiene una posición de dominio en el mercado ya que su coste es competitivo y permite la reutilización, sin que la reciente introducción del plástico, como materia prima sustitutiva de la madera, represente una amenaza real a medio plazo.

El poste de madera utilizado tradicionalmente en la construcción de invernaderos, como soporte perimetral y de interior, ha venido sufriendo un acusado proceso de desplazamiento por la adopción cada vez más frecuente de estructuras de tubo y perfiles de acero galvanizado. Así, a pesar de que la madera, todavía hoy, representa más del $75 \%$ de las estructuras de invernadero existentes, su uso restringe las posibilidades de crecimiento de la productividad, propia de una explotación agrícola moderna, dado que en la mayoría de los casos no permite una eficiente regulación del ambiente del invernadero, tanto por la escasa altura que alcanza como por la imposibilidad de incorporar los necesarios automatismos y maquinaria de control activo del clima.

En general se trata de empresas que se dedican tanto a la elaboración de envases como de palets cuyos eslabonamientos provinciales hacia atrás -en relación con los consumos intermedios- son muy débiles ya que se abastecen mayoritariamente en mercados extraprovinciales (Jaén, Huelva o Portugal), con una capacidad de producción excesiva en relación a la demanda y escasa capacidad de reacción a cambios de ésta.

\section{Agroquímicos}

En el sector de agroquímicos hay que distinguir entre el subsector de productos destinados a la protección y estimulación de los cultivos (pesticidas, fungicidas, herbicidas, bioestimulantes, etc.), y el de fertilizantes, tanto orgánicos (estiércol) 
como inorgánicos. Dentro de estos últimos es también posible diferenciar entre: fertilizantes simples, como el nitrógeno, el potasio y los fosfatos, los compuestos (mezclas físicas de simples) y complejos (mezclas moleculares).

En el ámbito internacional, el mercado de fitosanitarios químicos está controlado por empresas de alcance multinacional con sede social en Alemania, Francia, EE.UU, Suiza y Gran Bretaña. Los centros de producción de fertilizantes inorgánicos, por su parte, pertenecen a multinacionales con sede en Dinamarca y Holanda, mientras que el abono orgánico por su propia naturaleza tiene un carácter local o, a lo sumo, regional.

En Almería el sector se compone de un conjunto de empresas que básicamente se dedican a la comercialización de productos manufacturados fuera de la provincia. Sin embargo, algunas de ellas además de la distribución, también realizan tareas de fabricación de fertilizantes, entendiendo ésta como la mezcla de productos químicos prefabricados (fertilizantes compuestos) para conseguir un producto específico a las necesidades de la demanda.

La mayor parte de estas empresas son de capital almeriense, encontrándose entre ellas algunas procedentes de Valencia o Zaragoza, que orientan su actividad en un $90 \%$ al abastecimiento del mercado local. Aunque por lo general no realizan actividades de $\mathrm{I}+\mathrm{D}$, las empresas de mayor dimensión dedican una pequeña parte de sus gastos anuales a desarrollar productos más especializados y eficientes, en definitiva, más ajustados a las características propias de la agricultura de la zona, lo que inevitablemente genera innovación incremental.

\section{Colmenas}

Las condiciones de aislamiento y altas temperaturas que se alcanzan en el interior del invernadero hace que determinadas fases biológicas de las plantas como la fecundación, que por lo general se realizan de forma natural al aire libre mediante la intervención de los insectos, tengan que ser estimuladas artificialmente a través del aporte de fitohormonas, productos químicos sustitutos de las hormonas naturales. Sin embargo, el uso de estos fitorreguladores habitualmente lleva aparejado una serie de efectos adversos sobre el cultivo si no se administran correctamente, como el rajado, el ahuecado o deformaciones de frutos, y alteraciones en las cualidades organolépticas.

Aunque en la actualidad la utilización de estos fitorreguladores sigue siendo una práctica habitual en el $90 \%$ de la superficie invernada, para cultivos como el tomate, la sandia y el melón cada vez está más generalizado el uso de colmenas de abejorros.

Esta práctica muy extendida en los Países Bajos, por la gran hermeticidad de sus estructuras de invernadero, fue desarrollada inicialmente por dos empresas 
multinacionales de nacionalidad belga (Biobest) y holandesa (Brisa-Koppert) lo que les otorgó una posición dominante en el mercado internacional.

Actualmente existen varios empresas que se dedican a la producción y distribución de colmenas en Almería. Aunque para ser más precisos habría que deciı que sólo una de ellas se dedica a la fabricación ya que las otras dos delegaciones de venta de las empresas citadas con anterioridad que distribuyen las colmenas que producen en sus respectivos países.

\subsection{Servicios auxiliares}

\section{Transportes}

La condición de Almería como provincia periférica dentro de una región que se encuentra en la periferia de Europa, supone un reto añadido para el sector hortofrutícola. Esto exige de un sector de transporte capaz de garantizar el traslado de la producción hacia destinos lejanos (más del $50 \%$ a mercados internacionales y la mayor parte del mercado nacional a ciudades distantes más de $500 \mathrm{~km}$.) en condiciones óptimas de calidad y en los tiempos previstos.

En la actualidad el transporte por carretera es la modalidad de transporte dominante, básicamente por la inexistencia de una red de ferrocarril eficiente, y porque el transporte aéreo es extraordinariamente caro para hacer llegar la mercancía a cualquier país de Europa. La utilización del avión como medio de transporte de hortalizas al mercado de América del Norte es algo hastante habitual en Almería pero reviste poca importancia en términos de producción exportada.

El sector en Almería presenta, al igual que a nivel nacional, una estructura muy atomizada donde el número de autopatronos concentra el $50 \%$ del empleo y el $35 \%$ del parque de camiones; explicado en parte por la tendencia que se observa en las empresas del sector a convertir costes fijos en variables, bnscando incrementar la flexibilidad de su estructura ante las situaciones de demanda baja, tanto a largo plazo, dentro de los ciclos económicos de carácter recesivo, como a corto, para salvar las notables irregularidades estacionales en la demanda anual. De este modo, las empresas más grandes operan con un alto grado de subcontratación de flota, bien contratando autónomos que disponen de cabezas tractoras propias y pagan a modo de alquiler una cantidad por el uso del remolque, o directamente a autónomos que disponen del conjunto completo.

El capital invertido en estas empresas es de titularidad fundamentalmente provincial, y en su origen, es frecuente la vinculación directa con el cluster, haciendo de éste, un sector surgido endógenamente a raíz del crecimiento de la agricultura provincial habiendo aprovechado así esta ventaja de localización inicial para expandirse hacia otras áreas y productos. 
Los cada vez más exigentes estándares de calidad (puntualidad, seguridad, información) obligan a las empresas de transporte a introducir mejoras tecnológicas dirigidas a optimizar la planificación de las operaciones. Así, cabe resaltar que las empresas de mayor envergadura dedican una cantidad indeterminada a I+D en líneas como diseño y desarrollo de software y telecomunicaciones.

Los eslabonamientos hacia delante que establece la agricultura con este sector son extraordinariamente intensos, sin embargo, los efectos de arrastre que genera sobre el resto del entramado productivo son muy débiles ya que, aunque una flota de 1.900 camiones frigoríficos tiene una demanda de inputs considerable (combustible, neumáticos, piezas de recambio, talleres de reparaciones, sistemas de comunicación, instalaciones) que tienen por lo general un carácter local, la adquisición del camión, la compra de neumáticos y accesorios mecánicos se realiza a través de distribuidoras y delegaciones de venta de compañías que localizan sus centros producción, cuando menos, a nivel nacional.

Finalmente cabe resaltar que Almería es sólo una fracción del mercado relevante de las empresas de transporte de cierta dimensión, en la medida en que éstas definen sus estrategias a escala nacional e internacional tratando de complementar, a lo largo del año y en los trayectos de retorno, las producciones que se realizan en distintos espacios.

\section{Construcción de invernaderos}

La fuerte expansión anual que está conociendo la superficie dedicada a la agricultura intensiva en Almería (cerca de 1.500 ha.), junto a la renovación de las estructuras de las explotaciones en funcionamiento (un $2 \%$ de las hectáreas puestas en cultivo para 1998), hace que las empresas dedicadas a la construcción de invernaderos estén asistiendo a un momento dulce en su desarrollo, tanto por el actual volumen de negocio como por las perspectivas generadas por las obras hidráulicas de carácter público y privado en ejecución.

En Almería el sector de construcción de invernaderos lo forman entre 60 y 70 empresas, además de las cuadrillas que trabajan de forma irregular e introducen competencia desleal vía reducción de los costes físcales. En su mayoría son empresas de capital almeriense, cuyo origen se vincula a la actividad agraria, ya que son el resultado de la constitución en sociedad de profesionales autónomos que trabajaban con anterioridad en el sector. La actividad, como se ha apuntado antes, sufre una fuerte estacionalidad porque la renovación, reparación y mejora de estructuras se realiza cuando el ciclo de producción se detiene, viniendo a coincidir con los meses estivales. Esto tiene consecuencias sobre la estabilidad de la mano de obra del sector que está sometida a fuertes oscilaciones en su demanda, encontrando su punto álgido, como es lógico, en la época de verano; época que, por otra 
parte, coíncide con la máxima actividad en el sector turístico, lo que explica que la mano de obra temporal proceda básicamente de Granada y de los pueblos de] interior de Almería, existiendo fuertes déficits de mano de obra especializada en determinadas tareas del proceso de producción como fresadores y tomeros.

En cuanto a los consumos intermedios que demanda este tipo de actividad y su procedencia, aparte del plástico de cubierta y el $20 \%$ del utillaje adquirido en la provincia, el resto tiene su origen fuera de Almería: el alambre procede de Córdoba y Asturias y las estructuras metálicas de Castellón, Granada y Murcia.

En relación con la penetración de las empresas de Almería en los mercados extraprovinciales hay que hacer mención a las incursiones realizadas por algunas de ellas en mercados nacionales e internacionales, tales como Tenerife, México y Marruecos. Estas experiencias, aunque esporádicas y con un peso poco significativo en el volumen de facturación del sector, emiten señales muy positivas sobre su capacidad para diversificarse espacialmente en el caso de un hipotético estancamiento o retroceso de la demanda.

\section{Semilleros}

La función del semillero es asegurar la correcta germinación de la semilla y acompañar el crecimiento de la planta hasta el tamaño óptimo para poder ser trasplantada con éxito, minimizando el número de intentos fallidos que devenían del manejo de la semilla por parte del agricultor. Así pues, la actividad de este sector no es más que la externalización de un proceso que antes se hacía en la explotación agraria y que pretende aprovechar las ventajas de la especialización productiva.

En la actualidad el sector está formado por alrededor de 40 empresas entre las que destacan un pequeño grupo, que dispone de procesos de producción muy tecnificados, junto a un amplio número de pequeña dimensión con instalaciones manifiestamente mejorables.

Estas empresas son en su práctica totalidad de capital provincial y, aunque para encontrar el origen de la primera hay que remontarse en el tiempo 25 años, no ha sido hasta la última década cuando se ha asistido a un intenso proceso de creación de empresas; expansión con visos de continuidad, dadas las expectativas de crecimiento de la superficie invernada y, por ende, de la producción.

En relación con el consumo de inputs intermedios, las empresas que se dedican a esta actividad necesitan instalaciones de invernadero cuyos requerimientos son los propios, cuando menos, de las explotaciones agrarias, de modo que el origen de sus insumos debemos entender que es el mismo que en el caso de éstas últimas. Sin embargo, su especialización hace que el grado de tecnificación sea más intenso, incorporando instrumentos de control activo del clima y líneas de 
mecanización a lo largo de todo el proceso de germinación, crecimiento y clasificación de la planta, cuya procedencia se localiza en Cataluña fundamentalmente, aunque algunas líneas de siembra tienen su origen dentro de la provincia.

Aunque en la actualidad ya se está abasteciendo de plantas a Portugal y Francia, la experiencia acumulada a lo largo de los años y la importante especialización por productos que se observa en estas empresas, hace que estén situadas en condiciones de partida inmejorables para poder satisfacer la demanda de este tipo de servicios que proviene de otros mercados internacionales como Latinoamérica y el Norte de África.

El futuro del sector pasa, finalmente, por una mayor profesionalización de la gestión técnica y empresarial, un cambio en profundidad de las estructuras de explotación y la mejora de la productividad a través de la introducción generalizada de maquinaria en las líneas de riego, de siembra y de desinfección, así como en las líneas de clasificación y manipulación de producto.

\section{Servicios informáticos}

Aunque en este apartado se tratará de describir, con brevedad, el sector de las empresas especializadas en la elaboración de soluciones informáticas para la agricultura y actividades conexas, esta actividad no se restringe exclusivamente a ellas. De hecho, como se ha mencionado para otros sectores (transportes o sistemas de riego), las soluciones informáticas se desarrollan en buena parte dentro de las mismas empresas. De esta forma, el diseño del software para la gestión del módulo de fertirrigación corre por cuenta de las empresas que lo fabrican, mientras que las empresas de transportes de mayor entidad diseñan sus propios programas de gestión interna.

En Almería, el sector informático está muy concentrado en torno a dos empresas de cierta entidad, junto a un número reducido de empresas de pequeña dimensión. Su actividad se concentra en la distribución de hardware, desarrollo y comercialización de software y servicios de integración de sistemas, así como una intensa labor de formación a través de diversos tipos de cursos.

La oferta de productos informáticos se dirige a satisfacer las necesidades de un amplio conjunto de empresas relacionadas con la agricultura intensiva. Así, por ejemplo, las empresas manipuladoras y alhóndigas demandan sistemas de gestión administrativa, de personal, mercaderías (entradas -captura de datos desde la báscula-, ventas y control de almacén), control de envases, gestión comercial, pizarras electrónicas de subasta, terminales de información, etc. Pero también hay soluciones informáticas para Organizaciones de Productores de Frutas y Hortalizas (control de socios, previsiones de producción, informe de realizaciones), para técnicos agrícolas (codificación de datos, informes de campo, análisis de produc- 
ción, control de colmenas), semilleros (control de siembra, injertos, control d envases y bandejas, administración, control de cámara) y, como no, para agricul tores (gestión económica de la explotación, planificación de tareas, control d personal).

Son empresas, por otra parte, con un alto grado de profesionalización en st gestión y muy diversificadas. Además del abastecimiento de productos informático: al conjunto de empresas que gravitan en torno a la agricultura intensiva (al quє dirigen un $65 \%$ de su facturación) distribuyen también equipos de telefonía digita como agentes profesionales de marcas nacionales y equipos como ordenadores $\epsilon$ impresoras de las principales marcas del mercado.

Los eslabonamientos de arrastre que establece este sector con el resto del cluste son muy débiles debido fundamentalmente a que el grueso de los consumos intermedios (ordenadores, impresoras, interfaz, cables, etc.) se adquieren en su grar mayoría en territorio nacional, y en menor medida en el extranjero.

Estas empresas suelen dedicar más de un $10 \%$ de sus gastos anuales a realiza actividades de I+D, en líneas que buscan la optimización de soluciones en las instalaciones, mejora de los sistemas operativos, tecnología de comunicaciones e integración de elementos de electrónica industrial en los sistemas.

A modo de conclusión cabría resaltar que, aunque la adquisición y el adiestramiento en el uso de estos productos requiere cambios importantes de mentalidad en todo el entramado de agentes que interaccionan en el sistema, la opinión generalizada es que no existe una resistencia importante a la adopción de este tipo de tecnología y que el recambio generacional garantiza la continuidad de este proceso, sobre todo en las explotaciones agrarias, parte del sistema que podríamos entender como más reticente a la evolución, dado el menor nivel de formación de la mayor parte de sus propietarios.

\section{Asesoramiento técnico agronómico}

El crecimiento que ha experimentado la agricultura intensiva en estos últimos 20 años gracias a la continua incorporación de innovaciones, tanto en los aspectos relacionados con el manejo de la producción en las explotaciones agrarias, como por los desarrollos aplicados a los consumos intermedios utilizados por éstas, no podría entenderse sin considerar el papel que han jugado los ingenieros y técnicos agrícolas.

El número de ingenieros agrónomos e ingenieros técnicos agrícolas colegiados que prestan servicios de asesoramiento técnico agronómico en Almería es del orden de 800 , de los que los ingenieros técnicos agrícolas vienen a representar más del $90 \%$ del total. Si a éstos se suman los que habitualmente recorren, por motivos de trabajo, el arco Alicante-Málaga se entenderá por qué Almería es uno de 
los espacios con mayor densidad de profesionales dedicados al asesoramiento técnico agronómico por unidad de superficie.

Estos agentes son los protagonistas de buena parte de la emisión y difusión de la información en el sistema, soportada por un conjunto de canales articulados a partir de un entramado de relaciones que unas veces tienen carácter formal y otras informal.

Las relaciones de carácter formal se identifican con las funciones propias de cada agente en el desempeño ordinario de sus obligaciones laborales e institucionales. Así, los centros de investigación radicados en la provincia, fundamentalmente los centros de investigación experimental (CIFH y Las Palmerillas) y en menor medida la universidad, vierten al sistema de manera continuada, con carácter público los resultados de sus líneas de I+D. Los profesionales que trabajan en empresas industriales y de servicios, en el desarrollo de sus funciones de comercialización, hacen fluir la información en un doble sentido: hacia los técnicos de campo (y, en menor medida, a los agricultores) de las innovaciones que se van introduciendo en el mercado, y con carácter de retroalimentación, detectando las necesidades que surgen en las explotaciones agrícolas e informando, en su caso, a los departamentos de $\mathrm{I}+\mathrm{D}$ de las respectivas empresas.

Pero además de estas relaciones más o menos deliberadas que se establecen con claros fines informativos, los agentes se encuentran sometidos a los efectos sinérgicos que derivan del desarrollo de una actividad tan dinámica en un espacio muy reducido, creándose vínculos y contactos informales que de otra manera no se darían y que se refieren básicamente a los intercambios de información generados a partir de las relaciones sociales que se propician en ámbitos de esparcimiento.

\section{UN ANÁLISIS DE CONJUNTO}

Del análisis realizado se derivan las siguientes características más sobresalientes de las empresas y actividades consideradas:

1. El conjunto del cluster generó un valor añadido en la provincia de 471,40 millones de euros en 1998 en actividades vinculadas con la agricultura intensiva, que en algunos casos es el mercado exclusivo (semillas, construcción de invernaderos,...), mientras que en otras actividades es mucho más significativa la facturación a otras áreas de negocio (construcción, servicios informáticos). El empleo estimado vinculado con el cluster para el mismo año fue de 15.095 personas al año. Ambas magnitudes vienen a significar aproximadamente el 9,9\% del VAB provincial y el $10 \%$ del empleo, lo que si bien pueden parecer porcentajes bajos, cobran su importancia si se tiene 
en cuenta, por una parte, que en los años más recientes se está asistiendo un proceso de densificación del cluster y robustecimiento de muchas de su actividades y, por otra parte, que tanto o más importante que la entidad di sus efectos en términos de valor o empleo es la potencia transformadora de sistema productivo local.

2. Entre las actividades contempladas en el cuadro destacan las de manipula ción y comercialización de la producción hortofrutícola y su transporte, qu conjuntamente aportan el $58,6 \%$ del valor añadido del cluster y el $73 \%$ de empleo. Le siguen a gran distancia la parte del sistema financiero vincula da con el cluster (6,7\% del valor añadido), la construcción de invernadero $(5,2 \%)$ y la de construcción en general $(5 \%)$. Si a esto le sumamos las res tantes actividades de servicios, se comprobará que las actividades estricta mente industriales del cluster sólo significan el 7,5\% del valor añadido

MAGNITUDES BÁSICAS DE LAS ACTIVIDADES AUXILIARES

\begin{tabular}{lrrr}
\hline Sectores & $\begin{array}{c}\text { Valor añadido } \\
\text { Mill. de Euros }\end{array}$ & Empleo & $\begin{array}{c}\text { Exportación } \\
\text { Mill. de Euros }\end{array}$ \\
\hline Construcción & 23,44 & 400 & - \\
Maquinaria & 5,11 & 140 & - \\
Semillas & 12,62 & 350 & 12,02 \\
Plásticos & 20,73 & 325 & 39,07 \\
Sistemas de riego & 10,52 & 450 & 4,51 \\
Envases de cartón & 9,02 & 210 & 15,03 \\
Envases de madera y palets & 1,50 & 125 & - \\
Fertilizantes & 6,01 & 90 & - \\
Fitosanitarios & 6,91 & 70 & - \\
Abono orgánico & 1,95 & 90 & - \\
Comercialización & 179,10 & 8.500 & - \\
Transportes & 97,06 & 2.400 & 18,03 \\
Construcción de invernaderos & 24,34 & 325 & 3,01 \\
Semilleros & 7,21 & 350 & $*$ \\
Servicios informáticos. & 5,53 & 300 & 1,80 \\
Ingeniería y serv. empresariales & 9,02 & 150 & - \\
Abejorros & 0,54 & 50 & 1,14 \\
Extracción de minerales no met. & 2,70 & 125 & - \\
Servicios (limpieza, colocación) & 16,53 & 300 & - \\
Sector financiero. & 31,55 & 620 & - \\
& & & \\
TotaL & $\mathbf{4 7 1 , 4 0}$ & $\mathbf{1 5 . 0 9 5}$ & - \\
\hline
\end{tabular}

Fuente: Elaboración propia.

** sin datos 
3. Entre las actividades industriales se han incluido la producción de plásticos, semillas, sistemas de riego, envases de cartón, madera y palets, abono orgánico y abejorros. Buena parte de la facturación al cluster de estas actividades no tienen en Almería su base productiva, sino que en la provincia sólo se realizan actividades de distribución, como es el caso del input más cualificado tecnológicamente de la agricultura intensiva: las semillas. En algunos subsectores la base industrial provincial es sólida (plásticos, envases y embalajes), exportándose incluso una parte significativa de la producción provincial y, en otros casos, la función estrictamente industrial es relativamente escasa (maquinaria, agroquímicos), predominando la distribución o el montaje de componentes producidos fuera de la provincia.

Así, por tanto, si bien es interesante la construcción de una base industrial en tomo a la agricultura intensiva, el fenómeno no debe ser magnificado por su importancia productiva hasta el presente. Adicionalmente, la industria instalada no es de gran complejidad tecnológica, tiene escasas barreras de entrada, sus productos son fundamentalmente indiferenciados, poseen significativas economías de escala, siendo el precio el factor más determinante de su competitividad. Adicionalmente, la mayor parte de las actividades industriales están protagonizadas por empresas de iniciativa y capital externo a la provincia (con algunas notables excepciones), que se han instalado en Almería para suministrar a un mercado en expansión, no obedeciendo por tanto a iniciativas empresariales endógenas, lo que se explica por la falta de tradición industrial de la provincia y por las características de buena parte de los procesos industriales referidos: economías de escala, costes hundidos y operativa integrada en redes multinacionales en muchos casos.

Los caracteres señalados introducen cierta debilidad en el sistema, porque si bien las actividades industriales instaladas generan valor añadido y empleo en la provincia, colaboran en la creación de un clima industrial y en procesos de aprendizaje tecnológicos que no revierten todos su beneficios en la expansión del sistema productivo, no realizan en la provincia las actividades más cualificadas ( $+\mathrm{D}$, planificación estratégica) y pueden emigrar si las condiciones de mercado o cambios en la función de producción lo aconsejan.

4. La iniciativa local sí ha detectado y protagonizado la mayoría de las actividades de servicios en torno a la agricultura intensiva. En el sistema predominan las empresas de pequeña dimensión, aunque en las actividades más relevantes (manipulación-comercialización de hortalizas, transporte y sistema financiero) también participan empresas de dimensiones considerables y en otras (servicios informáticos) se van consolidando empresas de dimensión mediana. Como corresponde a un sistema cuyo nacimiento se vincula a una actividad principal bien definida, la mayor parte de las empresas muestran 
gran dependencia de la agricultura intensiva y de las otras actividades com plementarias del cluster, aunque en algunos casos se ha iniciado una diver sificación de los mercados, tanto por la atención a nuevos sectores de deman da como por su incipiente presencia en mercados extraprovinciales.

Así por tanto, la agricultura intensiva ha generado de forma indirecta, en sı entorno, un conjunto de actividades industriales y de servicios que amplifi can la trascendencia en términos de producción y empleo de la actividar primaria (los llamados «efectos mutiplicadores»). Para valorar la importan cia de estos efectos indirectos se ha estimado el multiplicador en 0,297 . S a los efectos indirectos añadimos los efectos directos (producción y empler hortícola) que vienen a significar un valor de 0,465 , tendremos un efects total estimado en 0,762 , de modo que un aumento o disminución de 1 ( millones de euros en la demanda final, se traducirá en un aumento o dismi nución del VAB provincial de 7,62 millones de euros.

Por otra parte, podría valorarse el efecto inducido derivado de la aplicaciór de la renta de los factores en la provincia. Lógicamente este efecto será má: intenso en la medida en que la provincia requiera menos importaciones part satisfacer la demanda interna. Para su estimación sería necesario dispone de una tabla input-output provincial; en su ausencia se recoge el valor co. rrespondiente a la economía andaluza que para el año 1990 fue del 0,46 sobre la expansión de la producción, lo que se expone solamente para indi. car un orden de magnitud de dicho efecto, pues es de todo punto de vist: incorrecto trasladar dicho coeficiente a Almería, dada la diferencia temporal, el mayor grado de apertura de la economía provincial y la diferent $\epsilon$ estructura productiva.

\section{EL SISTEMA PRODUCTIVO LOCAL}

Con el concepto de sistema productivo local se hace referencia a la conjunción de actividades económicas en el territorio vinculadas por lazos comerciales y de cooperación, que comparten un mercado de trabajo y conocimientos comunes, lc que proporciona al territorio economías externas, que son factores de competitividad añadidos a los propios de cada empresa. La existencia de este tipo de sistemas ha sido valorada por el análisis económico como soporte del desarrollo local y como motivo de atracción para la localización de nuevas actividades y empresas. Por tanto, es del mayor interés saber en qué medida la realidad productiva de Almería se aproxima a los esquemas ideales de los sistemas productivos locales y como podrían fortalecerse para potenciar el desarrollo provincial. El análisis de algunas de sus características puede aproximarnos a ese conocimiento, aunque sin duda exigirán investigaciones adicionales. 
A) La existencia de un mercado local propicia la ganancia de eficiencia productiva por disponer de los suministros necesarios, con un grado de especialización adecuado a los requerimientos de la demanda. También los mercados locales pueden permitir el abaratamiento de los costes de los inputs asociados a interrelaciones estables de las empresas en el territorio.

Las características de los mercados locales son identificables en el sistema productivo de Almería, ya que las empresas suministradoras de inputs, tanto a las explotaciones agrícolas como a los almacenes de manipulación y comercialización, están muy especializadas en el abastecimiento de productos y servicios adaptados a las especificaciones de la demanda: film con características técnicas bien definidas, módulos de fertirrigación a la medida de las unidades de explotación, semillas adaptadas a las condiciones climáticas locales, estructuras de invernadero que optimizan la ventilación y la captación de energía solar, maquinarias y sistemas de clasificación y envasado específico para las características de la producción hortofrutícola almeriense, envases de cartón más resistentes a la humedad y trayectos de largo recorrido, empresas de transporte con despliegue logístico adecuado, etc.

B) Las externalidades tecnológicas están asociadas a la difusión de la tecnología entre las empresas. Entendiendo el concepto de tecnología en sentido amplio -es decir, no sólo referido al conocimiento teórico o empírico aplicado a la producción que es susceptible de ser codificado, sino también el conjunto de conocimientos que está contenido en los equipos de producción, métodos, rutinas, formas de organización y, en general, en el «know how» de las empresas- se compartirá que un sistema productivo como el que nos ocupa va acumulando un acervo de conocimientos compartidos, que son posibilitados por los flujos de información entre las empresas e individuos a través de mecanismos de carácter formalizado (centros de investigación, tecnología incorporada a los inputs productivos, asesoría de técnicos agronómicos) o derivada de las relaciones informales de los agentes que participan en el sistema (agricultores, empresas de manipulación y comercialización, industria y servicios auxiliares). Estos flujos de información permiten que, en un espacio relativamente reducido, los conocimientos acumulados sean fácilmente difundidos, permitiendo que las innovaciones puedan ser adoptadas con rapidez y que se estimule la generación de innovación incremental.

Estas externalidades constituyen sin duda uno de los activos fundamentales y más sólidos del sistema productivo en torno a la agricultura intensiva almeriense, porque es la fuente principal de innovación y de ganancia de competitividad de la producción de la zona, máxime si tenemos en cuenta que buena parte de esos conocimientos compartidos son de carácter tácito, no fácilmente codificables, lo que les confiere un carácter de externalidad dinámica. 
C) Otra de las características de los sistemas productivos locales es la existen cia de un mercado de trabajo compartido, lo que representa beneficios tanto par: los trabajadores por la diversidad de alternativas de demanda de trabajo, como par: las empresas por disponer de una oferta de trabajo amplia y cualificada. Posible mente este rasgo no sea de la misma entidad que en otros sistemas productivos er los que los requerimientos de cualificación sean más compartidos. En el caso qu nos ocupa la demanda de mano de obra predominante (invernaderos y almacene: de manipulación y comercialización) es escasamente cualificada, aunque es mu】 considerable la de técnicos agronómicos, de gestión empresarial y otros técnico: en algunas de las actividades industriales y de servicio emergentes.

Lo que sí pone de manifiesto la experiencia es que los «spin off» son frecuen tes, tanto en su contenido específico, es decir, asalariados que deciden establece su propia empresa en el mismo sector apoyándose en el acervo de conocimiento: acumulados, como el caso más frecuente de creación de empresas para produci bienes o servicios que desde la perspectiva de la demanda no son suficientement atendidos por el mercado o pueden establecerse en él con márgenes de beneficio: considerables.

D) Con todo, lo que sí parece indiscutible, aunque no se disponga de informa ción objetiva que lo cuantifique, es la existencia de un ambiente empresarial esti mulante, en el que la sociedad valora muy positivamente el trabajo, el espíritı emprendedor, la asunción de riesgo, etc., propiciándose mecanismos de sinergia con una dinámica intensa de creación de empresas, también estimulada por la ca pitalización de las rentas generadas en las actividades primarias.

E) Otro de los rasgos característicos de los sistemas productivos locales má: dinámicos es la interacción existente entre competencia y cooperación. En el casc de Almería, la mayor parte de las actividades del sistema-particularmente la agri cultura intensiva- actúa en un marco de competencia, tanto con los mercados leja nos como con los estándares de precio y calidad del mercado local; pero ello no e: óbice para que se produzcan múltiples formas de cooperación empresarial, bien d mancra formalizada o colaboraciones puntuales para la resolución de necesidade: compartidas. Así, son muy numerosas las cooperativas de primer y segundo grado las asociaciones empresariales y otras instituciones de colaboración empresarial, lc que ha favorecido la presencia directa de la producción almeriense en los mercado: exteriores, ha permitido crear ferias y certámenes, racionalizar la extracción y dis tribución de agua, la construcción de desaladoras, el abaratamiento y regularizaciót de ciertos suministros o la creación de equipamiento hotelero de negocio. La coope ración se extiende a la investigación agronómica en algunos casos (entre empresa: de semillas o entre éstas y agricultores) o a la planificación de cultivos por las orien taciones de almacenes y cooperativas comercializadoras a los agricultores. 


\section{PERSPECTIVAS DEL MODELO (SISTEMA) PRODUCTIVO}

¿Es posible mantener este proceso de desarrollo productivo en Almería en los próximos años?. Y de ser así, ¿cómo podría ser intensificado?. Responder a esta pregunta exige examinar en perspectiva temporal las bases productivas sobre las que se asienta y las potencialidades y restricciones previsibles.

\subsection{Agricultura intensiva}

Las posibilidades de que se mantenga o aumente la producción hortofrutícola, y con ella la de las actividades industriales y de servicios vinculadas, dependerá del comportamiento de los mercados.

En cuanto a la demanda, el consumo de frutas y hortalizas en el mercado nacional y europeo no parece probable que se frene, sino que por el contrario, las tendencias en la dieta alimenticia parecen asignar una elasticidad de demanda-renta positiva y superior a la unidad para la mayoría de estas producciones. Adicionalmente, la incorporación de los mercados de Europa del Este e, incluso, la consolidación de algunos mercados más remotos (Estados Unidos, Canadá) si se reducen los costes de transporte, pueden augurar un aumento continuado de la demanda.

Pero además de lá cantidad demandada, es necesario tener en cuenta que, en mercados de altos niveles de renta y formación, los consumidores tienen en consideración de forma creciente la variedad, la calidad y características de la producción y sus procesos. Pues como está poniendo de manifiesto la experiencia reciente, los mercados demandan nuevas variedades, características organolépticas y de presentación más exigentes y, sobre todo, exigencias crecientes en los estándares medioambientales y sanitarios de producción y manipulación. La irrupción de los valores ecológicos en las sociedades desarrolladas y, en particular, de las dietas «sanas» está ampliando la demanda de la agricultura ecológica y forzando al control y limitación de inputs en la producción agrícola. Por estas razones, la limitación para la producción almeriense podría derivarse de los requerimientos ambientales, a no ser que se adopten -a ser posible adelantándose a las exigencias de los mercados- las medidas necesarias para el conjunto de la producción. Y se subraya «para el conjunto de la producción», porque también son imaginables los efectos negativos que para el conjunto de la economía provincial pudiera originar un episodio de contaminación o de vinculación de efectos nocivos para la salud con determinados tratamientos agrícolas.

En cuanto a la situación de los mercados, la competencia en los mercados tradicionales de Almería, siendo un asunto que ha preocupado, por los efectos de la ronda Uruguay y los compromisos de la Unión Europea con los países mediterráneos potencialmente competidores, en la actualidad la opinión compartida es que 
el fenómeno no es inquietante a corto o medio plazo. Ante las posibilidades d competencia futura, la forma más adecuada de hacerle frente no es reclamandc defensas proteccionistas, sino aumentando la competitividad propia vía innovaciór y eficiencia y colaborando con la hipotética competencia en determinadas fases $d \epsilon$ la cadena de valor, como por ejemplo, en la comercialización de su producción

En conclusión, si la producción va adaptándose a las exigencias de la deman. da y va expandiéndose a nuevos mercados, las perspectivas a medio plazo son $\mathrm{d} \epsilon$ aumento de la producción hortofrutícola y de las industrias y servicios del siste. ma vinculados. Por lo que el modelo productivo puede mantenerse e incluso aumentar su nivel productivo.

\subsection{Diversificación productiva}

Ahora bien, un sistema productivo tan especializado y dependiente de un único tipo de producto es mucho más frágil ante shocks externos que una economíc diversificada en sus fuentes generadoras de valor. En efecto, cambios imprevisibles y radicales en la demanda o en los factores de la producción hortofrutícola pueden implicar una crisis en el sector, que sería amplificada por los efectos multiplicadores al conjunto de la economía provincial.

Por ello tiene interés discutir si el enriquecimiento del sistema productivo local ha propiciado el desarrollo de actividades que gozan de cierta autonomía de la agricultura intensiva, produciendo para sectores distintos y/o mercados externos. De existir tales comportamientos el sistema productivo se enriquecería con la diversificación de actividades, limitaría su fragilidad y propiciaría una «reproducción ampliada».

Este fenómeno ha comenzado a producirse, pero de una forma incipiente. En algunas de las actividades que hemos caracterizado de industriales (plásticos, envases de cartón) parte de la producción se destina a la exportación, pero aún siendo estimable la aportación de valor y empleo para la provincia, se concreta en productos indiferenciados y sobre una base tecnológica no muy compleja, por lc que las economías de escala y de gama serán determinantes para la consolidación de las mismas en la provincia. Más importantes serían las exportaciones de semillas derivadas de la $\mathrm{I}+\mathrm{D}$ realizada en la provincia, y aunque existe este tipo de actividad, Almería es totalmente dependiente de la importación de semillas de empresas multinacionales. Más interesantes por los efectos tecnológicos y los intangibles afectados, son algunos diseños específicos derivados de la experiencia almeriense de maquinarias para almacenes de manipulación, la de los semilleros: los sistemas de riego, o la incipiente exportación de abejorros. También en actividades como los servicios informáticos o la construcción de invernaderos, algunas empresas almerienses comienzan a tener presencia en otras provincias españolas $y$ en el exterior. 
Consecuentemente, dado el interés que para la economía provincial tiene la diversificación de las actividades productivas basadas en la puesta en valor de conocimientos acumulados, es importante conocer cómo puede diversificarse la actividad productiva aprovechando los intangibles del sistema productivo y, en particular, qué puede ser vendido en mercados extraprovinciales. La respuesta a esta pregunta lógicamente han de darla los empresarios locales que son los que descubrirán las posibles oportunidades de negocio, combinando la detección de huecos de mercado con la disponibilidad de intangibles y de los restantes factores de producción, correspondiéndole al sector público, o a otras instituciones que quieren fomentar el desarrollo provincial, el papel de estimulador de las posibles iniciativas.

Lógicamente, esa deseable diversificación se alcanzará profundizando en las actividades actuales o conexas a las desarrolladas en el presente. Así por ejemplo, pueden apuntarse: la extensión del diseño de software a medida a otros sectores productivos, la fabricación de maquinaria para la manipulación de frutas y hortalizas, la fabricación de plásticos para usos diferentes a los invernaderos, la extensión del sistema de transporte a otros productos y provincias, y la posibilidad de extender el servicio a centros de stockaje y distribución, aprovechar la experiencia de comercialización para extenderla a otros productos no necesariamente provinciales, la constitución de empresas de servicios integrados para valorizar la experiencia acumulada en la construcción y gestión de invernaderos en otros países, etc.

Estas u otras iniciativas han sido pensadas por algunos empresarios locales, que en muchos casos no toman las decisiones de inversión por el riesgo que puede significar, porque los niveles de rentabilidad en las actividades que desarrollan le resultan suficientes o porque las inversiones requeridas superan sus posibilidades. $\mathrm{Y}$ es en casos como éstos en los que se requiere la cooperación empresarial y en los que el papel del sector público u otras instituciones que fomentan el desarrollo local deben actuar como catalizador del sistema, si se comparte que la diversificación productiva puede ser crucial para el desarrollo de Almería.

\subsection{Restricciones al desarrollo}

Hasta aquí se han examinado las potencialidades de la economía almeriense sobre la base de la agricultura intensiva y de las actividades vinculadas a ésta; pero si bien las potencialidades son ciertas, en la economía provincial también son identificables algunas restricciones que pueden cuestionar e incluso imposibilitar el desarrollo. Identificarlas y valorar su importancia es un ejercicio imprescindible para poner las bases para su resolución. 
1. Las insuficientes infraestructuras son una restricción para el desarrollo eco nómico provincial que afecta a casi todos los sectores productivos, máximı en una provincia geográficamente periférica y dependiente de los mercado: europeos tanto para la agricultura como para el turismo. A pesar de la: importantes inversiones realizadas en los años reeientes, la Mesa dt Infraestructuras de Almería viene llamando la atención a las Administracio nes Públicas responsables sobre la necesidad de resolver algunas limitacio. nes provinciales entre las que destacan la continuación de la autovía Puertc Lumbreras-Adra en dirección a Málaga, la conclusión de la A-92 Sur, la conexión ferroviaria con el Euromed y la conexión a la red de gas nacio. nal. La demostración de la efíciencia relativa de las inversiones demanda. das sobre la base de rigurosos auálisis económicos será el argumento fun. damental para demostrar la justeza y oportunidad de las dichas actuaciones

2. Otra de las restricciones posibles para el desarrollo provincial puede derivarse de las características del mercado de trabajo. En diversas entrevistas con los agentes económicos se ha puesto de manifiesto la escasez de manc de obra en los momentos altos de la temporada agrícola, la no siempre adecuada formación y las restricciones a la legalización de los inmigrantes que trabajan en los invernaderos. A estas limitaciones propias del mercado d $\epsilon$ trabajo español (insuficiente movilidad y agilidad administrativa) hemos de sumarle la que puede ser fundamental restricción en el medio plazo: la insuficiente formación profesional. Si bien hasta el presente las actividades dominantes han exigido escaso grado de cualificación profesional, el deseable desarrollo de nuevas actividades industriales y de servicios requerirár formaciones específicas que, además del aprendizaje por la práctica, tendrár. que estar soportadas por una formación académica y profesional, para lo que debe existir una oferta educativa adecuada. Lo reseñado tiene particulat relevancia para la formación empresarial, que si bien hasta el presente ha sido compensada por el trabajo, la experiencia práctica, la intuición y el sentido común, en el futuro será recomendable que a estos activos imprescindibles se les una la formación específica.

3. Existe otro grupo de restricciones al desarrollo provincial de carácter medioambiental. Entre éstas ya se ha hecho referencia a la problemática que puede derivarse de los contenidos químicos en la producción hortofrutícola si no se ajustan a los estándares de los mercados de destino.

4. La dinámica de desarrollo acelerado de la agricultura intensiva en el territorio y el aumento de la productividad como norte que ha guiado la actuación de los agricultores, ha propiciado que la atención se centre en el interior de los invemaderos sin reparar en lo que generaban en su entorno. En ausencia de normas reguladoras e intervenciones públicas que ordenasen el espacio rural, el aumento de la eficiencia productiva también ha significa- 
do la aparición de impactos ambientales que, con mayor o menor intensidad, provocan externalidades negativas a los mismos agricultores y a otras actividades productivas. Entre éstas cabe mencionar el problema de los residuos, tanto orgánicos como plásticos, sobre los que sí existen algunas iniciativas municipales de recogida y otras de reciclaje, y el de la ordenación de un espacio rural que, por su singularidad, debe ser abordado desde una perspectiva supramunicipal al menos en el Poniente, en el que la dotación de adecuadas vías de comunicación, recogida y canalización de aguas pluviales, recogida y tratamiento de basura y desechos, e infraestructura energética y de telecomunicación, debe de abordarse con criterios semejantes a los polígonos industriales.

5. También el desarrollo de la agricultura intensiva ha significado una competencia por el suelo con otras actividades económicas como el turismo y una restricción al mantenimiento de espacios naturales. Éste es el caso del municipio de Níjar, mientras que en Roquetas de Mar y El Ejido se produce la mayor concentración de invernaderos y también de turismo, que compiten por el uso del territorio, por el agua e, incluso, por la arena, significando también un impacto visual las singulares extensiones de invernaderos, de difícil valoración económica.

6. También de difícil valoración económica, pero con trascendencia a largo plazo para la provincia, es el crecimiento desigual de la población en el territorio, con una elevada concentración en buena parte de los municipios costeros, mientras que en el interior de la provincia se ha ido produciendo un vacío demográfico, con una población con alto nivel de envejecimiento y coincidiendo con los espacios de mayor desertización.

7. Pero entre todas las posibles restricciones para el desarrollo futuro de Almería es la hidrológica la de mayor importancia tanto por la escasez de agua como por su calidad. Aún habiéndose producido enormes avances en las ganancias de productividad por metro cúbico, la expansión incontrolada de superficie invernada ejerce una fuerte presión sobre la oferta hídrica de difícil cuantificación por ser básicamente de origen subterráneo. Esta presión se manifiesta a través de síntomas inequívocos de degradación de los acuíferos tanto por el decreciente nivel piezométrico como por la progresiva salinización que se observa en las zonas próximas al mar. La resolución de este conflicto con graves repercusiones tanto medioambientales como socioeconómicas pasa no sólo por incrementar la oferta a partir de la instalación de centrales desaladoras sino por acometer un mejor estudio de la capacidad y evolución de los acuíferos que permita establecer un adecuado marco de regulación de la demanda. 


\section{BIBLIOGRAFÍA}

ARTHUR, W.B. (1990): «Sillicon Valley locational cluster. When do innovation return inplay monopoly». Mathematical Social Science, $\mathrm{n}^{\circ} 19$.

BANDRÉS, E. (1993): «Las infraestructuras políticas y realizaciones», en España, economía Espasa Calpe, Madrid.

CALATRAVA REQUENA, J. (1998): «La investigación socioeconómica sobre el sistemć hortícola almeriense: consideraciones, factores limitantes y tendencias», en Seminario de Ciencias Hortícolas. Universidad de Almería, Almería.

CALLEJÓN, M. y COSTA, M.T. (1995): «Economías externas y localización de las actividades industriales», Economía Industrial, nº 305.

COROMINAS, J. (1998): «La infraestructura hidráulica de regadío en Almería», en El sector agrario y agroalimentario del año 2000. Instituto de Estudios Almerienses, Almería.

DOLADO, J. y OTROS (1994): «Convergencia económica entre las provincias españolas: evidencia empírica (1955-1989)». Moneda y Crédito, $\mathrm{n}^{0} 198$.

ESCOBAR LARA, A. (1998): «Aspectos ambientales de la agricultura en invernaderos», en Curso Superior de Especialización sobre tecnológica de invernaderos 11. Consejería de Agricultura y Pesca. FIAPA. Caja Rural de Almería.

FERNÁNDEZ LAVANDERA, O. y PIZARRO CHECA, A. (1981): «Almería: la técnica del enarenado transforma un desierto». Revista de Estudios Agrosociales, no 115.

FERNÁNDEZ, A. (1997): «La agricultura del año 2000 en Almería», Andalucía Económica, $\mathrm{n}^{0} 83$.

FERRARO, F. J. (Director) (2000): El sistema productivo almeriense y los condicionamientos hidrológicos. Ed. Civitas.

KRUGMAN, P. (1991): "History and industry location the case of manufactoring belt». American Economic Review, n" 89.

LUCAS, R. E. JR. (1988): "On the mechanics of Economic Development» Journal of Regional Science, $33(2)$.

MAS, M. y otros (1994): «Capital público y productividad en las regiones españolas». Moneda y Crédito, $\mathrm{n}^{\circ} 198$.

MOLINA HERRERA, J. (1991): Necesidades y problemática del sector comercializador de frutas y hortalizas de la provincia de Almeria. FIAPA, Almería.

PALOMAR OVIEDO, F. (1994): Los invernaderos en la provincia de Almería. Instituto de Estudios Almerienses, Almería.

ROMER, P. (1986): «Increasing Retums and Long-Run Growth». Journal of Political Economy, 94 , octubre.

ROMER, P. (1990): «Rendimiento crecientes y nuevos desarrollos en la teoría de crecimiento», Cuadernos Económicos ICE, número 46. 